\title{
Appraisal of transport infrastructure for pedestrians in the city area, the case of Pardubice
}

\author{
Josef Bulíček, Pavlína Brožová
}

Universtity of Pardubice, Faculty of Transport Engineering, Studentská 95, CZ-53210 Pardubice, Czech Republic

ABSTRACT: The paper is focused on pedestrian traffic in city area of Pardubice. Three localities are characterized in the first part of the paper. Each of them is illustrating one different problem of pedestrian transport. The first locality is a rush interchanging node of urban public transport located on both sides of a rush street. Problems related to passengers crossing this street by interchanging are highlighted. The second locality is representing a problem of decision between pedestrian level crossing or underpass. The third locality is representing a place with complicated interaction between transport participants (pedestrians and cyclists) in the case of limited spatial conditions. Unintuitive using of traffic marking and traffic signs is also mentioned. Proposed measures for improving of conditions in pedestrian transport are mentioned in local as well as general points of view. Second part of the paper is focused on conditions for pedestrinas along one of the most frequented pedestrian routes in Pardubice. This route is connecting the main railway station and the city center (Pernštýnské Square). Pedestrian crossings and individual segments of this route are considered independently. Presented appraisal can be used as a theoretical base (example-based) for appraising of other pedestrian routes as well. Possible measures for improving of conditions in pedestrian transport are mentioned in the paper as well.

KEYWORDS: cyclist transport; conflict in utilization of transport infrastructure; Pardubice; pedestrian; pedestrian crossing; road; transport; underpass; urban area.

\section{INTRODUCTION}

Walking (pedestrian transport) is a perspective mode of transport for accessibility of city centres or central business districts (CBD). Pedestrian transport has got social, environmental and health related benefits Soni et al., (2016). Other benefits are mentioned by Wicramasinghe et al., (2017). These benefits are: health effects, burning of calories, no emission of greenhouse gasses and no (reduced) demand after parking places for cars.

Relative short distances and a number of destinations able to be reached by walking are making walking attractive in CBDs. Public passenger transport is a support for pedestrian transport as well Dhanani et al., (2017).

Suitable conditions for walking (pedestrian transport) belong to a set of essential presumptions for improvement of attractiveness and modal share of pedestrian transport not only in CBDs.

The aim of this paper is to appraise conditions for pedestrian transport in Pardubice. There is an effort to find results with potential to be generalized.

Pardubice is a city (ca. 90,000 inhabitants) located in the Czech Republic, $100 \mathrm{~km}$ to the east of the capital Prague. The city is a regional centre with a relative rush traffic.

Cycle transport plays very important role as well. Cycling is frequently used in Pardubice due to flat terrain. Number of measures making cycling more attractive and accessible is realized in the city next to it.

There are two main problems in pedestrians' point of view occurred in the CBD of Pardubice: necessity to cross rush streets (roads loaded by relative high volume of car traffic) and interaction with cyclists. These two problems are highlighted in this paper. This is not an individual problem of Pardubice only. Relative high speed of car traffic as well as cyclists on pavements are identified as problematic factors by Ausserer et al., (2013) in Vienna as well.

Appraisal of infrastructure configuration and conditions for pedestrians is made in this paper.

There are two different main approaches in the paper. The first is focused on selected problematic 
localities. Each of these localities is appraised as a point - one single place. Two criterions are used for selection of these localities - the volume of traffic and a problem registered at place (in relation to pedestrian traffic).

The second approach represents an appraisal of selected pedestrian route as a line. This approach is inspired by Sissiopiku et al., (2003), but with difference. There is not considered one street with different pedestrian facilities like in the paper Sissiopiku et al. (2013), but one route used by a lot of pedestrians coming to Pardubice (by train or bus) and going from the main railway station (or central bus station) to the CBD by walk. Total length of this route is $1.74 \mathrm{~km}$. End of this route is in historical square named as Pernštýnské Sq. This route is also used by a lot of pedestrians walking in part of this route only.

This area is served by a number of bus and trolleybus lines of urban public transport, so that people have an alternative, how to travel here. Bicycles and cars are also significant alternatives in general point of view, but utilization of these alternatives is limited by people coming by train or bus to Pardubice from surroundings.

This is also very important fact. Improvement of modal share for pedestrian transport is related to quality of whole transport chain (e.g. train/bus + walking; car driving and parking + walking or combinations with utilization of urban public transport).

'Isolated' improvement of conditions for pedestrians can attract people making their journeys in the area of the city only. The aim is not to attract urban transport passengers, but state-of-art car users. Optimization of (long-distance and regional) public transport is not a scope of this paper. One of important parking lots for reaching the CBD is located in front of the main railway station. This parking lot can be used as 'Park\&Ride' or 'Park\&Go'. This can also improve importance of appraised pedestrian route and attract more pedestrians.

The aim of this paper is to analyse conditions for pedestrians, to characterize and evaluate problems occurring by walking and to point out them. Some proposals for possible improvement of pedestrians' conditions are mentioned. This paper can be also used as an example-based tool for possible identification of problems in pedestrian transport in other cities.

\section{Important notes}

All of the measures (proposals for improvement) are proposed individually by authors. They are not based on any official plans, projects etc. (the exceptions are significantly commented in the text). These proposals are not expressing any official attitude of the city of Pardubice or any other authority or institution. Any official and detail feasibility study is not realized (including economical consideration). Due to these facts, realization of any of measure is not possible without more detail verification of all conditions. Verification of a measure especially in technic, construction, economic and all other relevant feasibility points of view is obligatory before a measure will be enforced in practice. On the other hand, all measures have been proposed with an effort to be realistic. The effort is to contribute to public and professional discussions about improvement of conditions for pedestrians. We are opened to all inspiring opinions and ideas, able to develop this research.

There are used some data based on transport surveys in this paper. These surveys were realized by a number of university employees and students in the frame of practical education. Thanks belong to everybody cooperating on this systematic surveying process. The authors are attended in a team responsible for design and conduction of all of these surveys.

\section{PEDESTRIAN IN THE LAW POINT OF VIEW}

It is important to mention, which participants can be met on infrastructure for pedestrians. It is also crucial to understand which needs, requirements and conditions they can have.

The concept of pedestrian is defined by the Act No. 361/2000 Coll. in the Czech Republic. Naturally, pedestrian is a person going by walk. On the other hand, pedestrians are also persons pushing or pulling:

- sledge,

- baby pram,

- wheelchair,

- pushcart with the width not exceeding $600 \mathrm{~mm}$,

- bike,

- motorcycle with the volume of cylinders to $50 \mathrm{~cm}^{3}$,

- or a person accompanying a dog.

Persons moving by skis or roller skates and wheelchair users are also pedestrians.

It must be pointed out, that a cyclist accompanying a bicycle is a pedestrian according to Act No. 361/2000 Coll. This is necessary for understand- 
ing to rules valid for this cyclist as well as for data processing.

Pedestrians are not allowed to use a car route if a pavement (sidewalk) is available. Pedestrian must look around before crossing. Crossing is not allowed between parked vehicles (cars). Marked pedestrian crossings, underpasses or overpasses must be used, if available. Traffic signs (incl. traffic light signals) must be followed and respected by pedestrians. Pedestrian must not enter a lane for cyclists in front of a riding cyclist. If a cycle lane and a pedestrian lane are divided, a pedestrian is not allowed to enter the lane for cyclists with exception of some defined cases. Some of these exceptions are: circumvention of an obstacle, turning out or in a pavement etc.

There are pointed out rules, which are important for the walking in the city areas. Not all valid rules are mentioned.

When pedestrians are crossing a (car) road, they are obligated to cross the road perpendicularly to axis of a road. Pedestrians are obligated to use right side of zebra crossing. Pedestrian must not force car drivers to change speed or direction of drive suddenly.

In spite of the fact that these rules are clear, a number of conflicts related to these rules is occurring in practical operation.

Definition of traffic signs is taking part of the Regulation No. 294/2015 Coll. (in actual form) issued by the Ministry of Transport of the Czech Republic.

Question is if these rules are suitable for pedestrians nowadays. This can be a good framework and a good starting point. It can be fully valid for a rush roads or areas lying out of city etc., where a car transport is necessary and functional. On the other hand, it can be too strict to pedestrians in city centres, CBDs etc. Car traffic should be calmed and pedestrians preferred in such areas to make a better public space. Measures like pedestrian and living zones are at disposal. Problem is if these zones can be applied. Car traffic load is high and possibilities to calm the traffic are limited in many cases.

\section{DECISION ABOUT MOVEMENT OF PEDESTRIANS IN SPACE}

It is necessary to understand, how pedestrians are choosing their routes. Model mentioned by Pöschl et al., (2011) is designed especially for modelling of pedestrians' movement (and decision making). On the other hand, this principle can be used for illustra- tion of pedestrians' decision making in reality as well. This can determine a point of view, in which the infrastructure will be appraised. Background for design of transport surveys will be created in this way.

Pedestrian is more autonomous in comparison with cars. Cars are leaded by lanes on a route. Pedestrian is more independent in selection of route on a pavement. Basic factors influencing movement of a pedestrian (Pöschl et al., (2011)) are:

- destination of walk - local destination in space, which is visible from actual pedestrian's position, as well as 'global' destination for all journey,

- effort to circumvent obstacles,

- effort to hold a distance from other pedestrians,

- effort to adapt the walk to other (known) pedestrians (incl. so called herd behavior),

- information at disposal.

Speed of traffic flow (walking) is decreasing in relation to increasing traffic flow density. It is similar like by car flows. This is crucial for evaluation of bottlenecks like narrow spaces, underpasses (subways) or overpasses, passes through various buildings etc. Pöschl et al., (2011).

\section{ANALYSIS OF STATE-OF-ART KNOWLEDGE}

This chapter provides an overview about some of published methods and approaches. This analysis creates a background for appraisal of conditions for pedestrians in Pardubice.

Movement of pedestrians, cyclists and cars in the city area is a scope of a number of papers and articles. The paper Dhanani et al., (2017) is focused on 'transport demand' after pedestrian transport. His case study is realized in the case of London. Modelling is based on Shannon formulas (entropy). Complex overview of transport demand modelling is provided by Ortúzar et al., (2001). Mathematical modelling (prognosis) of pedestrian transport demand is not followed in this paper (case study of Pardubice). Appraised localities were identified in other ways. Transport flow modelling will be needed in the case if intensities of pedestrian flows will be significant for appraisal. Transport demand models (providing information about traffic load) can help by identification, where it will be effective to realize possible measures. In other words, how many pedestrians can profit from it. 
The paper Füssl et al., (2017) is focused especially on cyclists, but the approach is inspiring. Cyclist identity and cyclist's interactions with other transport participants are considered individually. Unfortunately, there is not too much room for elaborating of similar concepts for pedestrians in this paper. On the other hand, it is necessary to distinguish roles of individual participants of transport process. Other important fact is, that driving licence ownership can also modify behaviour in other roles (if a car driver come in a role of a pedestrian or a cyclist). 'Driving licence ownership' is often reflected feature by surveying due to this, e.g. Füssl et al., (2017), Räsänen et al., (2007). Every pedestrian has an individual style of walking. Different conditions to walk are caused by different body size or used clothes and other factors Hariyono et al., (2017). Different needs are occurred also by visually impaired people using special infrastructure, e.g. guiding lines. Koštálová et al., (2016).

Examination of pedestrian behaviour and perceptions is provided also by Sisiopiku et al., (2003). The study is focused on one of boulevards located close to campus of the Michigan State University in East Lansing (USA). Surveyed boulevard is equipped by different pedestrian facilities. Signalized crossings are also taking an important part of this consideration. An important part of interviewees (17\%) marked, that traffic lights (long crossing times) can keep people off from walking in Vienna Ausserer et at., (2013). So, signalized crossings must be taken into appraisal of pedestrians' conditions as well. Pedestrian-driver encounters, communication and decision strategies are presented in the paper Šucha et al., (2017) for the case of Olomouc (the Czech Republic).

\section{RESEARCH DESIGN AND METHODS APPLIED}

As it follows from the Introduction of this paper, research is designed in two different ways for individually appraised localities and for a whole pedestrian route appraised as a line. Following text is outlined as a description of carried-out research. This text can be also used as a manual for appraising in other cases (e.g. in other cities). Some comments, how the results can be applied (for a general case) are also mentioned.

\subsection{Individually appraised localities}

Research for individual localities is designed according to each individual locality and surveyed problems. a) Criterions for selection of localities

Three localities as examples have been selected by these criterions:

- problematic place from operational point of view,

- problems are related to pedestrians,

- some problems (accidents) were happened at the locality and they are registered in the database GIS 'Unified Transport Vector Map' UTVM, (2017) in 10.5 year long time frame (1 January 2007 - 1 July 2017),

- ability to provide an example to other cities.

Localities with different problems have been selected to be presented.

\section{b) Methods}

Modified way of analysis is applied for each locality due to the fact, that localities with different problems are reported. The methods (approaches) are characterized for all cases in the chapter 6 .

Transport surveys based on counting of users (using the infrastructure in selected time frame) are applied. The way of infrastructure utilization is distinguished.

\section{c) Conflicts}

In spite of the fact that numbers of registered accidents (investigated by police) are relative small, small-sized problems in operation are occurred very often. These conflicts are taken into consideration as well, because they can be a base for possible accident. Definitions of conflicts are mentioned in the chapter 6 by each individual case.

\section{d) Aim of surveys}

The main aim of these surveys is to illustrate a traffic situation at selected localities, incl. rate (number) of possible conflicts. Contemplation of possible measures for improvement of situation and generalized recommendation for other localities (cities etc.) are added.

\subsection{Pedestrian route as a line}

The second part of research is focused on the whole pedestrian route as a line connecting the main railway station and historical centre (Pernštýnské Sq.). There are mentioned reasons (criterions) for selection of this route in the chapter 1 - Introduction of this paper. 


\section{a) Survey structure}

The route is consisted of two kinds of elements - pedestrian crossings and route segments. All of these elements are appraised.

\section{b) Methods - appraisal of pedestrian crossings}

The paper Sisiopiku et al., (2003) is providing a base for appraisal of pedestrian crossings. There are examined different pedestrian facilities by Sisiopiku et al., (2003). A little bit modified approach is applied in this paper - the route is appraised in the pedestrian's point of view. The set of considered elements (pedestrian facilities) is determined by location on this route.

There are used two indices for examination of pedestrian crossings by Sisiopiku, et al. (2003) - spatial and temporal crossing compliance rates.

Both rates are representing a ratio of a part of pedestrians using the facility in an appraised way to all pedestrians using this facility. Temporal facility expresses a ratio of pedestrians coming to a signalized crossing while a green ('WALK') signal is lighting to all (total number of) pedestrians using this crossing. Sisiopiku et al., (2003).

The authors of this paper apply temporal crossing rate presented by Sisiopiku et al., (2003) also for the case of Pardubice. All 4 signalized pedestrian crossings located on the appraised route (between main railway station and the city centre) are examined by using this method. Partial modification of this index has been made.

This modification is related to the fact, that it is not necessary to consider all pedestrians as individuals. There is an aim to illustrate, how an individual pedestrian can use the infrastructure (signalized pedestrian crossing). Modified temporal crossing compliance rate $(M T C C R)$ is applied for that reason. MTCCR can be calculated by formula (1) as a ratio between the length of a green signal per one signalling cycle $\left(t_{g}\right)$ and the total length of this signalling cycle $\left(t_{c}\right)$.

$$
\operatorname{MTCCR}=\frac{t_{g}}{t_{c}} \quad[.100 \%]
$$

The value of MTCCR can be also represented as a probability, that a pedestrian will come to a crossing, when the green signal will be lighting. Influence of pedestrian traffic flow specifics can be decreased in this way. MTCCR can be more objective, because it is related to a crossing itself and not to a variedness in pedestrian flow.

Spatial crossing compliance rate (SCCR) is defined by Sisiopiku et al., (2003) as a ratio of pedes- trians using marked crossing $\left(n_{a}\right)$ to all pedestrians crossing the street in the 'attraction area' of that pedestrian crossing $(N)$, see formula (2). Spatial crossing compliance rate is not applied in the case of Pardubice. The problem when pedestrians are crossing roads at unmarked places is not considered as significant in Pardubice. On the other hand, this index can be also potentially helpful for possible application in different conditions, if problem of mistaken utilization will be significant.

$$
S C C R=\frac{n_{a}}{N} \quad[\cdot 100 \%]
$$

\section{c) Methods - appraisal of route segments}

Background for appraisal of route segments can be represented by methodologies applied by Soni et al., (2016) and by Wicramasinghe et al., (2017). Both methodologies are designed for evaluation of pavements and traffic operation on pavements.

Wicramasinghe et al., (2017) are using these criterions: width, pedestrian flow rate, presence of obstacles and presence of handrails. There are defined 3 levels of service (quality) according to these criterions. Soni et al., (2016) are using space $\left(\mathrm{m}^{2} /\right.$ pedestrian), flow rate (pedestrians/min by $1 \mathrm{~m}$ of pavement) and speed $(\mathrm{m} / \mathrm{s})$ for determination of level of service at each segment of appraised pedestrian route. 6 levels of service (corresponding to $\geq 85 \%$, $\geq 60 \%, \geq 45 \%, \geq 30 \%, \geq 15 \%$, and $<15 \%$ level of compliance) are used for pavement appraisal by Soni et al., (2016).

Pedestrian flow rate is mentioned in both methods. Problem of this index is, that its value is changing in time. It is a kind of dynamic index.

Pedestrian flow intensity of 400 pedestrians/ hour was surveyed in traffic peak (working day, $7: 10-7: 40 \mathrm{AM})$ and 140 pedestrians/hour in offpeak time (working day, 6:30 - 7:00 PM) on selected route.

This paper is focused especially on infrastructure appraisal, dynamic indices will not be incorporated in research. Other criterion is presence of handrails or fences. There are no serious problems with escaping of pedestrians from pavement (sidewalk) on this route or problems caused by overcoming of altitude differences in Pardubice. On the other hand, it can be a suitable criterion if these problems will appear.

Following criterions are utilized in this research (for Pardubice): pavement width, presence of ob- 
stacles and average pedestrian speed in 'uncongested' (free) conditions. Surveyed values will be commented in the way of limits based on Soni et al., (2016) and Wicramasinghe et al., (2017). This is applied for general appraisal of the whole pedestrian route.

Type of pavement surface and form of leading of cyclist transport are commented next to it.

\section{d) Aim of survey}

The aim of appraisal is to provide an illustration about situation in pedestrian traffic. Possible problems will be outlined. Contemplation of possible measures for improvement of situation (conditions for pedestrians) will be added as well.

Notice: if such specific appraisal method or approach is applied for individual place, this method is characterized directly in the chapter 7 of this paper.

\subsection{Overview of all appraised infrastructure}

There are considered :

- 1 not-signalized pedestrian crossing (in the middle of Masaryk Sq.),

- 1 signalized pedestrian crossing in combination with 1 nowadays closed and unutilized underpass (Sq. of Republic)

- 1 street segment with problematic interaction with cyclist traffic (17 November St.)

in the part of survey focused on individual localities.

There are commented 9 pedestrian crossings in the frame of route appraisal (main railway station city centre). 4 crossings of them are signalized, 3 are marked as places for crossing with no yield of pedestrians only, last 2 crossings are 'standard' marked zebra crossings. The number of 7 street segments on this route is appraised next to it. Appraised route is consisted of streets: Jan Perner Sq., Palackého St.. Míru St., Sq. of Republic and Zelenobranská St. The last pedestrian crossing on this route (the closest one to the historical centre) is considered also as an individual locality (signalized pedestrian crossing together with closed underpass).

There are surveyed in total 10 pedestrian crossings ( 4 signalized and 6 not-signalized, incl. 3 places for crossing) and 8 street segments. All of these localities are lying in the CBD of Pardubice or in close surroundings (at the main railway station).

\section{PROBLEMATIC LOCALITIES IN PARDUBICE IN THE POINT OF VIEW OF PEDESTRIAN TRAFFIC}

There are mentioned 3 examples of individually appraised problematic localities in the CBD of Pardubice. Mentioned problems are related to pedestrian traffic or to interaction of different subsystems of transport (incl. users of these transport subsystems, transport participants). Principle how these localities has been selected is mentioned in the chapter 5.1. of this paper.

\subsection{Pedestrian crossing Masaryk Square (Masarykovo nám.)}

Masaryk Sq. is one of the most frequented places in Pardubice loaded by a high volume of route (car) traffic as well as a high volume of pedestrian traffic. This street is consisted of 4 lanes for road traffic, which are separated by a middle strip. This street is equipped by 3 stops for urban public transport and 2 stops for regional bus transport. These stops are located on both sides of this street, so that it is often necessary to cross the street (car route) by interchanging between different lines (buses). This set of stops is the main interchanging node of public transport in the CBD. Traffic flow of interchanging passengers (pedestrians in this case) is significant.

Surveyed marked pedestrian zebra-crossing is located in the middle of Masaryk Sq. It is a not signalized crossing nowadays (2017). This pedestrian crossing (Fig. 1) is also important for connection of the neighbouring shopping centre with the city centre. This is also an important part of intensity of pedestrian traffic flow (crossing the street here).

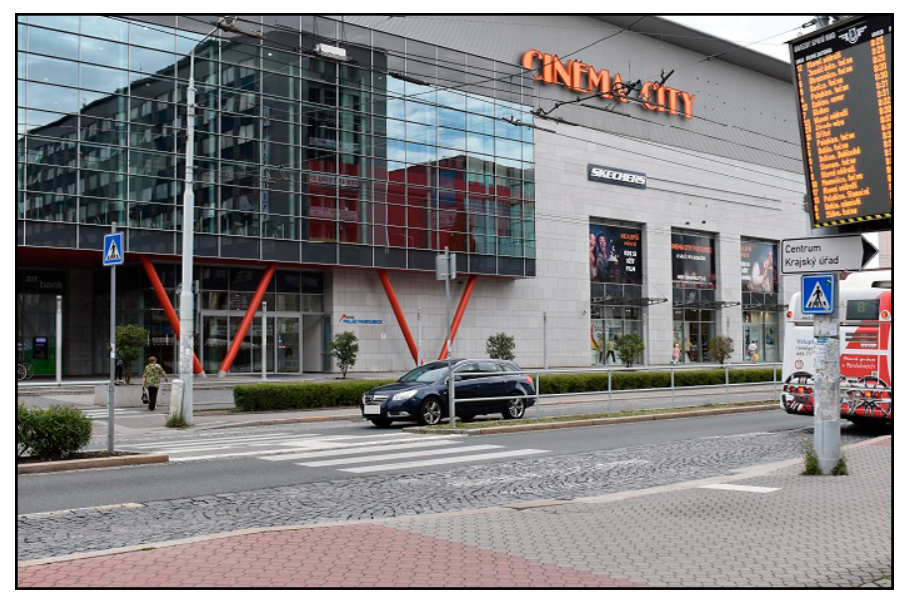

Figure 1. Surveyed pedestrian not signalized zebra-crossing, Masaryk Sq. Source: photo authors. 
The number of 10 traffic accidents is registered (police investigated) here in 10.5 years long time frame (1 January 2007 - 1 July 2017) in UTVM, (2017). 7 persons were light injured, 2 severe injured and 1 died. Each of these accidents represents 1 injured (in one case unfortunately died) person (especially pedestrian).

There is one important historical fact and experience connected to this location in the point of view of pedestrian transport. This zebra-crossing was not realized in former state. Place for crossing was been realized here only. Crossing was allowed, but with no yield for pedestrians. Preferred access route from one street side to another (also used for interchanging) was routed over a set of 1 not-signalized and 2 signalized zebra-crossings located at the junction of Masaryk Sq. with Míru St., Palackého St. and 17 November St. (southern end of Masaryk Sq.). The length of this diverted route is $330 \mathrm{~m}$. It was discovered, that it is not suitable solution for central interchanging node of urban public transport. Discussed not signalized zebra crossing has been realized here as a measure. It is also not too much suitable and installation of traffic lights is discussed nowadays.

Transport survey (presented in the paper Brožová et al. (2015)) was realized by students of Jan Perner Transport Faculty (nowadays Faculty of Transport Engineering) here on Thursday 25 June 2016. Total number of people crossing at this place (pedestrians and persons with bicycle) is 10,852 users in the time period of 12 hours $(10,418$ pedestrians and 434 persons with bicycle). Maximal registered number of users passing per one hour is 1,305 users. The share between pedestrians and persons with bicycle is 96:4 \%. Persons with bicycle and pedestrians are evaluated together in this case, due to the fact, that cyclists are not allowed to ride here! Cyclists respecting transport rules and getting-off a bicycle by crossing belong to pedestrians. So, differing of users between cyclists and pedestrians is not clear due to this. For that reason, total numbers are preferred and a specific category 'persons with bicycle' is applied. There is not a legal possibility to cross this street (Masaryk Sq.) by riding on a bicycle.

Problem is that $31-38 \%$ (ratio vary in time) of registered persons with bicycle are driving on this zebra-crossing. In spite of the fact, that it is very rush place with a lot of people and cars.

Crossing of interchanging passengers may be also a serious problem. This problem occurs especially when connecting bus is physically arriving or stand- ing at the stop on the opposite side of Masaryk Sq. if passengers are leaving the first bus. Passenger can enter the pedestrian crossing with reduced attention to road operation due to an effort to catch the bus on opposite side. Crossing of pedestrians can be realized in an unexpected way. This can be also a base for conflicts and possible traffic accidents.

\section{Contemplation of possible measures:}

There is not too much possibilities, how to contribute to improving of pedestrian comfort at this place. Relocation of urban public transport interchanging node is not possible due to limited space in the CBD and connection to the road network. Possibilites to calm traffic are also limited, because this street belongs to main roads in the CBD. City bypass in this direction (north-south) is existing in the west of the city now (roads I/36 and I/37), but important car traffic flows (from/to CBD) are remaining. Official plan discussed nowadays (2017) is to install traffic signals on this pedestrian crossing. This measure can improve safety, but it will have also some disadvantages. The first is possible negative impact on traffic fluency, especially on urban public transport. Synchronization of 3 traffic signalizations (at both junctions creating borders of Masaryk Sq. and on this pedestrian crossing) can be complicated due to variable dwell times of individual urban public transport vehicles (depended on alighting and boarding of passengers) at these stops. Disadvantage for pedestrians and especially for interchanging passengers can be, that the crossing time will be extended by waiting for a green signal. It can be longer than waiting on stopping (yielding) car. Realization of these traffic signals can be recommended in safety point of view, but some negative effects in compliance can occur.

Possibilities to calm the transport are limited at this place. Bus lanes were applied here a few years ago. Bus lanes were a reason for serious traffic congestions. Off-peak (11 - 12 AM) traffic intensity identified here is 400 vehicles/hour in one direction. Peak intensity (4-5 PM) is 600 vehicles/hour in one direction and traffic congestions are occurred. Average speed of vehicles is $31.5 \mathrm{~km} / \mathrm{h}$ by approaching to pedestrian crossing. This value is measured for first vehicles in platoons according to Räsänen et al., (2017). These cars are driving independently. Other vehicles are driving usually more slowly, especially if some vehicles are standing in front of the pedestrian crossing. Relative high speed of cars is an important factor decreasing quality of walking as Ausserer et al., 
(2013), mention it. Traffic calming can be possibly effective in off-time periods. It will be not effective in peak times, because a row of vehicles is moving slowly in this area. Possible extension of travel times (caused by transport calming measures) can make congestion more serious. Replacement of bus lanes can be an evidence.

Other supporting measures can be:

- improvement of marking of pedestrian crossing, e.g. different colour of surface under the zebra-crossing or other suitable graphical highlighting, this can partially contribute to decrease speed of approaching cars.

- change of placement of traffic signs - vertical traffic sign informing about pedestrian crossing is placed on one post together with lighting information table (urban public transport departures) and with traffic sign informing about direction to city center and to the regional authority, this post is located on the end of pedestrian crossing (see Fig. 1),

- information campaign about risk of quickly and inattentive crossing by interchanging (e.g. posters in urban transport vehicles), various local public actions related to transport safety (for pedestrians, cyclists as well as drivers), notification in education at schools in Pardubice etc.,

- police enforcement - it is recommended to focus this enforcement on prohibited cycling, in the case of future installation of traffic lights also on crossing by a red signal. There can possibly occur a group of interchanging passengers able to ignore a red signal when their bus will be arriving or dwelling at the opposite side of street.

\section{Generalized recommendations for other cities} based on this analysis:

- it is not suitable to design rush interchanging nodes with diverted (long) approaching routes between stops,

- combination of an interchanging node located at rush heavy-loaded street and level pedestrian crossing can cause operation problems, passengers interchanging in a hurry can pay inadequate attention to crossing,

- volume of pedestrians can be amplified by location of an entrance to shopping center or to similar object, if it will be located in the area of an interchanging node. Evaluation of this amplification is recommended in project phase.

\subsection{Pedestrian crossing located in Square of Republic (nám. Republiky)}

Second locality is signalized zebra-crossing (Fig. 2) located in the Square of Republic in front of historical Green Gate to the city centre. There is also a rush street consisted of 4 lanes separated by middle strip on northern side of crossing. Junction of streets Sq. of Republic and Míru St. is located directly on the southern side of this pedestrian crossing.

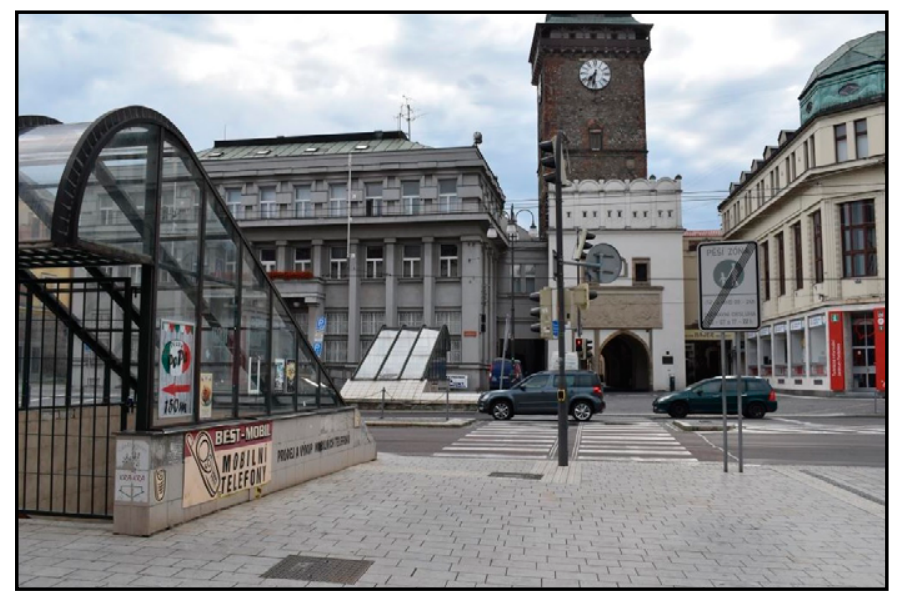

Figure 2. Signalized zebra-crossing together with underpass, Sq. of Republic. Source: photo authors.

4 accidents in connection to pedestrians are registered at this locality in 10.5 years long time frame (1 January 2007 - 1 July 2017) in UTVM, (2017). Each of these accidents causes 1 light injury (one person). Important fact is that 2 of these accidents were caused by pedestrians.

Historical development of this place represents important experience as well. This place is equipped by pedestrian underpass (subway). Construction of this underpass was started in 1971 and underpass was opened in 1973. Underpass was equipped by escalators. Demand after utilizing of this underpass decreased after setting escalators out of operation (in 90's years). Public demand caused, that this level pedestrian crossing has been realised as well. It was constructed as a not signalized pedestrian crossing. Crossing was equipped by car retarders to decrease speed of traffic. These retarders were removed due to negative influence of tremors on buildings in surroundings. Safety was improved by installation of traffic lights after replacement of retarders. 
State-of-art signalized crossing is preferred by pedestrians, so that the underpass has been rebuilt to a restaurant. Nowadays this restaurant is closed due to serious disrepair of the underpass and the future of the underpass itself is uncertain. It is confirmed, that underpass can be considered as an obstacle in walking by pedestrians.

Problem is that state-of-art solution (signalized crossing) is not safe. This level pedestrian crossing is the last from a set of 7 pedestrian crossings located on $650 \mathrm{~m}$ long Sukova St. Attention of drivers may be decreased due to a relative high density of subsequent pedestrian crossings (every ca. $90 \mathrm{~m}$ in average). On the other hand, this street (Sukova St.) looks like an 'express' city main road in the most of its length. This is in contrast with this end located directly in historical centre at a rush place with a rush pedestrian traffic.

Average approaching speed of vehicles coming from Sukova St. is $33.9 \mathrm{~km} / \mathrm{h}$ in uncongested conditions according to orientation measuring realized by authors. Passing times at two subsequent places were recorded for randomly selected vehicles driving independently as the first in a platoon of vehicles (according to Räsänen et al., (2017)). Measured average speed is about $4 \mathrm{~km} / \mathrm{h}$ higher in comparison to average speeds measured in Olomouc by Šucha et al., (2017).

Time space between passing of the last not signalized pedestrian crossing and this signalized crossing is 7 seconds in average (there is a distance of $65 \mathrm{~m}$ ), see Fig. 3. This can be another reason for possible driver's inattentiveness of drive. A car driver must during this time:

- become familiar with information, that next street going to right is a pedestrian zone (traffic sign is visible in Fig. 3),

- check, if a car is driving in correct lane,

- overtake a bus if bus is dwelling at a bus stop located here,

- recognize the color of signal on traffic lights,

- evaluate situation at two streets going from/ to right - the first (going out of a parking lot) is close in front of the signalized pedestrian crossing and the second (Míru St.) is situated close behind. It looks like a signalized junction (not pedestrian crossing only), Fig. 3.

Second reason may be, that this is a relative rush place with traffic lights only for pedestrian crossing.
Next junction is directly connected to this pedestrian crossing and it is not signalized. This can put increased demands on attention (especially in the case of drivers passing here for the first time). Public transport stop and way out from parking lot are located close in front of this pedestrian crossing as well. This can be also a fact complicating clear arrangement of the locality.

Illustration of view of approaching car driver is provided by the Fig. 3. Analysed signalized zebracrossing is located in the 'middle of picture' (Fig. 3) behind a bus stop. Other pedestrian crossing (the $6^{\text {th }}$ in order on Sukova St.) is located in forefront of the Fig. 3. It illustrates the problem with high density of crossings at this street as well. Commented parking lot with a way-out situated directly in front of (analysed) signalized zebra-crossing is placed on the right (way-in is in forefront).

The problems with attention in this area can be also validated by a total number of all 124 traffic accidents with 37 injured persons investigated in the area of Sq. of Republic in last 10.5 years UTVM, (2017).

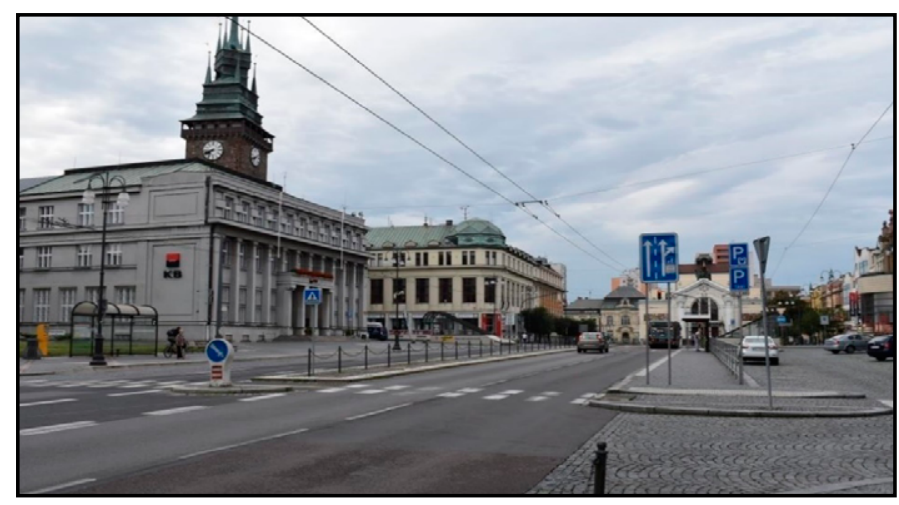

Figure 3. Signalized zebra-crossing (a view of approaching car driver), Sq. of Republic. Source: photo authors.

It is possible to make following conclusions. If the way for pedestrians is routed in such diverted way, like here by underpass (on different vertical levels as well), the way must be able to be passed in a very simply way.

Barrier-free access for people with reduced mobility and orientation is needed to be ensured in the case of using underpasses as well. If this will not be ensured, level-crossing restriction is not able to be recommended. Minimally, the $6^{\text {th }}$ pedestrian crossing in Sukova St. must remain in the case, if the underpass will be renewed without barrier-free access. If the underpass will remain, it is necessary to renew this underpass in a 'modern style' - making the way attractive. Easy and barrier-free access is a presump- 
tion. Attractiveness can be improved also by extension of underpass width and by placement of some commercial activities (e.g. newsstands, small shops) into underpass.

There can be also found some foreign studies as an inspiration how to consider this problem. Study elaborated by Räsänen et al., (2007) is focused on using of pedestrian bridges (overpasses) in Ankara. There are compared two bridges (overpasses) with similar features related to bridges and to road operation on crossed routes as well. Altitude difference can be overcome by escalators in the first case and by standard staircases in the second case. The first one (with escalators) is used by $62.9 \%$ of pedestrians crossing the road in this area. The second one (normal staircase) is used by $31.9 \%$ pedestrians only. Note: these values can be considered also like spatial crossing compliance rates (SCCR), applied by Sisiopiku, (2003). Relative high utilization rate in the first case is reached due to escalators and fences along the road as well. The conclusion can be, that escalators can improve compliance level, but it is not a complete solution. Additional measures, like physical blocking of level-crossing, are helpful as well.

Unfortunately, it is not possible to measure utilization rate of escalators at this location in Pardubice. It is about 25 years, when escalators were set out of operation (and removed after it). Relevant data from that time are not at disposal.

There is a question, why people are willing to use risky route (level-crossing) in spite of possibility to cross in a safe way by underpass (or overpass). This is a part of scope of the paper Rankavat et al., (2016). Personal safety is also an important reason. This is expressed by the fact that $14 \%$ of females attended in that survey never use underpasses in Delhi. There is also mentioned in the study Rankavat et al., (2016), that the willingness to use underpasses and overpasses decreases with rising age of people. It is possibly related to overcoming of altitude differences. On the other hand, the study Räsänen et al., (2017) from Ankara do not confirm this.

It can be found out by studying of both studies Räsänen et al., (2017) and Rankavat et al., (2016) that pedestrians are considering time spent by crossing, possible diversion of access routes (expressed by observing of number of staircases in Ankara), personal safety and a level of compliance. These features must be followed by planning of such pedestrian facilities like underpasses and overpasses. The results of the project COST 358, (2011) are that safety measures will not increase the willingness to walk. If the underpass can be used more, it must be attractive to come there as well. The underpass must be a part of public space to be utilized by pedestrians.

\section{Contemplation of possible measures:}

- due to the fact that existence of the underpass in the future is uncertain now (2017), it is necessary to presuppose, that the level pedestrian crossing will be existed in future as well (minimally in such time frame before potential reconstruction of underpass will be finished), replacement of this level crossing is not possible to be proposed at this time),

- first of all, conditions for paying attention of car drivers must be improved, it can be realized e.g. in the way of placement of additional traffic signs announcing this pedestrian crossing. The second measure can be speed limit of $30 \mathrm{~km} / \mathrm{h}$ calming the traffic in Sq. of Republic or placement of a distant traffic signal in front of this pedestrian crossing providing advance warning, that it will be necessary to stop (alternative to speed limit reduction). Similar signalling system is applied at junction of routes I/37 and III/32226 in PardubiceDražkovice, due to speed limit of $70 \mathrm{~km} / \mathrm{h}-$ mentioned signalized junction is located out of the city area,

- police enforcement - pedestrians crossing by red signal; car drivers driving by red; crossing at places out of marked signalized zebracrossing,

- to consider the possibility of underpass re-opening with additional measures - replacement of level signalized zebra crossing, construction of fences or other barriers at level crossing, allowing of barrier-free and simply underpass utilization (creating of ramps for access to underpass or installation of escalators and lifts), ensuring of safety in underpass and improvement of attractiveness to use the underpass.

\section{Generalized recommendations for other cities} based on this analysis:

- if an underpass can be applied, easy and comfortable access must be ensured, barrier-free access is recommended, using of underpass must be attractive for pedestrians, 
- time for using of underpass must be suitable (not too much longer in comparison with level crossing), uninstallation of escalators caused decrease of demand after utilizing of this underpass and a public requirement for level crossing in this case - make a carefully consideration by proposing of such changes decreasing pedestrian compliance, consider carefully the extent of facilities in the case of newly designed infrastructure,

- using of underpasses has not $100 \%$ compliance, additional measures supporting underpass utilization, like e.g. replacement of level crossings, construction of fences and other barriers are recommended.

\subsection{Street of ' 17 November' (tř. 17. listopadu)}

The street of ' 17 November St.' is led under a set of two bridges. These bridges are creating multilevel crossing with the street 'Hlaváčova St.' and the railway line Praha - Česká Třebová. Pavements (sidewalks) for pedestrian traffic are located at both sides of the 17 November St. in this area. Problem is, that each cycle track is realized as one-way lane for cyclists only due to limited space (Figure 4). Lanes for cyclists located on pavements are marked by a red colour of surface, pictograms of bike and arrows marking allowed direction of cyclists' ride. The problem occurred at this place is based in interaction between pedestrians and cyclists due to relative narrow space.

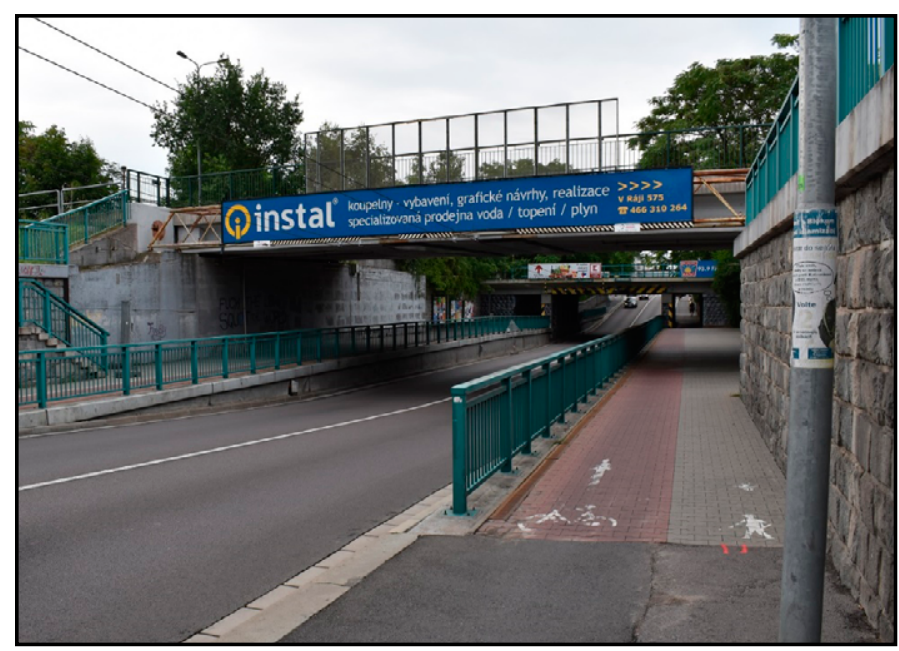

Figure 4. Segment of the 17 November St. Source: photo authors.

Occurred problem can be decomposed into two parts. The first is riding of cyclists in an incorrect direction (each of two lanes for cyclists on each pavement are one-way only as it is described above). Pedestrians are not inviting if a cyclist is coming in a wrong direction. They possibly pay no attention to this. This problem is more serious by pedestrians going here for the first time. Full respect to (horizontal as well as vertical) traffic signs can escalate this problem, if they do not know the practical operation.

The second part of problem is, when pedestrians enter (cross) the cyclist lane. If both problems are occurring together, this can make problem also more serious.

There is registered 1 traffic accident between cyclist and pedestrian with 1 light injury in the UTVM, (2017) during last 10.5 years. This is not a serious number, but small conflicts (able to be a base for an accident) are occurring every day. It can be illustrated by transport survey Bulíček et al., (2014), which is mentioned in following text.

Traffic survey at this locality was realized on 27. June 2014, $14-16$ hrs on the western pavement (sidewalk) of the 17 November St. The number of cyclists registered is 283 (per 2 hours) and 56 of them were driving in wrong direction toward city centre on the western pavement (it represents $19.79 \%$ of all cyclists passing here during the survey).

Second identified problem is that pedestrians are entering the lane for cyclists, 17 conflicts were registered during survey ( 2 hours). 1 conflict was caused by cyclist. More details to this transport survey and locality are available in the paper Bulíček et al., (2014).

Last, but not least, problem at this locality is, that traffic marking is not too much intuitive here. The path in entering area is declared as 'collective lane' with no spatial division due to narrow space in entering area of this locality and two lamp posts located in a 'pedestrian part'. It is marked by vertical traffic sign No. C 9a and it is also highlighted by traffic sign No. A 22 'Other danger' equipped by the text 'Path for pedestrians and cyclists is collective in the whole width of path' (detail, Fig. 5). It is correct, for entering area. Under the bridges there is a 'divided path' for cyclists and pedestrians marked by the horizontal traffic marking only. Vertical traffic sign No. C 10a for 'divided path' is missing there. Due to the fact, that vertical signs are prior and no junction is located between these two places, pedestrians and also cyclists can become uncertain if the horizontal marking applied under the bridges separating cycle and pedestrian lanes is valid or not. Situation is visible in the Fig. 5. The authors are sure, that different meaning of both signs C 9a (divided path) and C 10a (collective path) is sig- 
nificant and an adequate application of both of these signs can be helpful for orientation,. Example of this locality (compare Fig. 4 and 5) illustrates this.

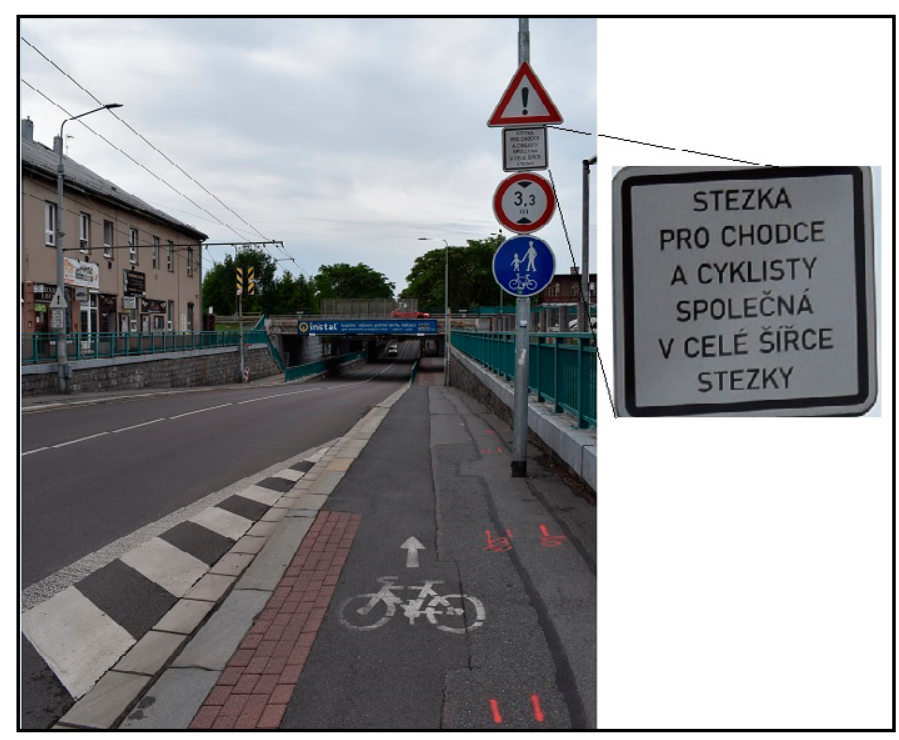

Figure 5. Traffic signs, 17 November Street. Source: photo authors.

Conflict in this case is usually not a such serious traffic accident, but a situation when somebody must suddenly change direction of movement or the speed of movement. So, compliance of using this infrastructure can be seriously decreased.

It can be said as a conclusion, that not all places are able to be equipped by transport infrastructure allowing ideal operational conditions. First of all, it is about thoughtfulness of all transport participants one to each other.

\section{Contemplation of possible measures:}

- possibilities to infrastructure changes without serious construction works (investments) are limited, because spatial conditions are limited here,

- possible extension of width of pavements can be helpful, but it is not able to be realized without deep economic analysis of effectivity (it is related to high volume of construction works with serious demands on costs),

- lanes for cyclists are marked by different colour of surface now, so that it is not able to be proposed this as an improving measure,

- extension of lanes for cyclists to approaching area (towards city center) is not possible due to limited spatial conditions (lack of space for pedestrians, because lamp posts are placed in pedestrian lane), Fig. 4.
- thoughtfulness of all transport participants one to each other must be improved by extension of transport education, especially education out-of-schools for wide cyclist and pedestrian public (in general, this education can be also focused on car drivers, but car drivers are not taking part in characterized problem occurred at this location). If this education will be realized in Pardubice, this place can be pointed out in a particular way. In the case of education in other cities this locality can be introduced as an example of possible problem, potentially occurred at similar localities,

- 'sensible' utilization of traffic signs - if a cyclist is coming to this area in restricted direction of drive, there are no vertical traffic signs with meaning 'end of one-way cyclist path operated in reverse direction' on the ends of one-way lanes for cyclists. Car drivers (and cyclists) are used to use these signs at ends of one-way streets - marked by traffic sign No. B 2). Traffic situation is explained in other way at cyclist one-way routes - cyclists are not allowed to enter this area, because any of traffic signs No. C 8a, C 9a or C 10a (allowing cyclist's ride) is not placed here. This situation is possible according to valid rules, but problem is, how it is intuitive for cyclists. Experience by marking used for one-way streets is going against this. For that reason a 'sensible' utilization of traffic signs, which will be more self-explanatory, is recommended,

- replacement of the situation with difference in vertical and horizontal marking for cyclists coming in direction out of CBD (to south) causing such uncertainty now,

- control of mistaken (prohibited) using of transport infrastructure by police,

- in the case of persisting problems, riding of cyclists can be fully forbidden at this place by transport sign No. C 14a equipped by the text 'Cyclist, get-off a bike'. Travel times of cyclists can be extended and compliance decreased by this measure, but it will be realized in the frame of safety improvement. (Driving of cyclists at parallel car road can not be recommended, because of spatial conditions and the high volume of car traffic).

Proposal leading to forbidden of cycling is illustrating also one of general crucial question - what is an aim - to open as most as pos- 
sible cycle paths in the frame of the city (also with the possibility of some conflicts) or to allow some interruptions of paths for cyclists. Naturally, in minimum cases only, if it is really necessary and any other suitable solution is not existed (e.g. due to spatial or operational reasons). The way of restrictions, in spite of that it is not ideal, can help to improve thoughtfulness of all transport participants.

The aim is to create an opinion, that anywhere where it is possible, cycling is preferred and suitable conditions for cycling can be created. On the other hand, responsibility of cyclists to get off a bike and make space also for other transport participants, if there are really complicated conditions and some limitations, belongs to this target opinion as well. This must be also added for making of 'sustainable' conditions in city transport as well. On the other hand, also pedestrians must be led to this thoughtfulness as well. For instance, entering of lanes for cyclists by pedestrians can be punished as well, if this lanes will be significantly, clearly and intuitively marked and also if there will be suitable conditions for walking (e.g. not a pedestrian lanes with lamp posts located directly 'in the middle' etc.).

\section{Generalized recommendations for other cities} based on this analysis:

- to take care about 'sensible' (clear, intuitive and self-explanatory) application of vertical and horizontal traffic signs,

- to replace possible uncertainties in traffic marking (placement of traffic signs),

- to explain correct traffic organization by different form of traffic education (schools in surrounding, public actions, preventive police actions, campaigns in local media etc.). A mention, what can be happened in the case of incorrect utilization of such infrastructure is also important in the frame of transport education, education can be prepared in general way, but this locality can be used as an example for example-based education,

- police enforcement at problematic places.

One next more general problem can be opened by this locality as well. The problem is if it is suitable to change regimes of transport organization frequently, like in this case.
The 17 November St. is $515 \mathrm{~m}$ long in this segment (between two subsequent road junctions) and there are applied 3 regimes, how the cyclist transport organized is (in direction out of the city center):

- collective ride in a car lane together with cars,

- 'collective' path for pedestrian and cyclists,

- 'divided' path for pedestrians and cyclists.

On the other hand, this is only one way, how to ensure as highest level of comfort and compliance for cyclists as possible (without no important costs for extended infrastructure reconstructions). This can support the idea, that it is not simple to create this level of comfort, but a lot of measures are realized. For that reason, it is a responsibility of each individual road user (pedestrian, cyclist and car driver as well) to use this infrastructure thoughtfully to compensate e.g. negative influence of changes in regimes of transport organization.

\section{PEDESTRIAN ROUTE BETWEEN MAIN RAILWAY STATION TO THE CITY CENTRE, LINE APPRAISAL}

Route between the main railway station and the historical square (Pernštýnské náměstí) is one of the most important and frequented routes for pedestrians in Pardubice. The length of this route is $1,740 \mathrm{~m}$. The city of Pardubice is located in a flat terrain, so that there are no serious ascents or descents at selected route. This fact is also an advantage for pedestrian transport.

Pedestrians are obligated to cross 9 marked pedestrian crossings or places for crossing located on this route in average distance of $290 \mathrm{~m}$ (notice: there are two 'sets of crossings', where 3 or 2 crossings are located very close one to another and for that reason the average distance is calculated as $1,740 \mathrm{~m} / 6$ places $=$ $290 \mathrm{~m})$. Three from these pedestrian crossings are equipped by traffic lights. Not signalized crossings can be mentioned, because ca. $36 \%$ of car drivers give not preference to pedestrians in situation if they are obligated to do it. This result is based on the paper Šucha et al., (2017) related to traffic situation in Olomouc. Pedestrian crossings represent $6.5 \%$ of length of this whole route from railway station to city centre.

These pedestrian crossings and one 'little' square in Havlíčkova St. are dividing appraised route into 8 route segments. Route segments are usually corresponding to block of houses. 
All these pedestrian crossings as well as all these route segments will be taken into consideration as the elements of route.

The route is led in a relative free space in the first part in Perner Sq. and Palackého St., in other words between main railway station and Hlaváčova St. (central station for regional and long-distance bus lines). Second part between Hlaváčova St. and the 17 November St. is surrounded by panel housing development and the street is equipped by a number of shops in ground floors of buildings. Third part is a newly reconstructed Míru St. with calmed traffic (living and pedestrian zones with limited operation of trolleybuses). This street is also able to be categorized as 'shopping promenade'. The last part is historical Zelenobranská St. led through historical city gate.

Almost $50 \%$ of pedestrian route is covered by asphalt surface, the rest is covered by different types of cobblestones or paving.

\subsection{Interaction with cyclist traffic}

There is a possibility to use a bicycle on whole route (from railway station to historical centre) as well. The way of integration of cyclist traffic on this route is characterized in the Table 1.

This is necessary to be mentioned, due to the fact, that a way of cyclist transport organization is essential for appraisal of interaction between cyclists and pedestrians on this route. This interaction belongs to generally identified problems, which pedestrians are facing to in the all Pardubice city area.

It can be said, that there are adequate conditions for cyclist traffic. Cyclist transport is segregated from the route for pedestrians in the most of length (89.9 \%). This is also effective for pedestrians, because they are not obligated to follow, which part of divided pavement is dedicated to them. They are not facing to possible problems related to quickly or inattentive cyclists' drive and to problems by meeting or overtaking manoeuvres. Cyclists are also not disturbed by pedestrians entering lanes for cyclists. Examples of such conflicts in Pardubice are mentioned in the paper Bulíček et al., 2014.

The most problematic at this route are the places, where relative strong pedestrian and cyclist flows are intersecting, namely Perner Sq., and a junction of Havlíčkova St. and Palckého St.

The pedestrian route will be characterized in following chapters according to 8 route segments and 9 pedestrian crossings. Route segments and pedestrian crossings will be characterized step by step in order from the main railway station to city centre. The structure of characteristics of each element is: general description, figure (photo) and 'unified' table with basic features.

All the appraisals are made for southern pavements of all streets located at this route. It is due to the fact, that it is more utilized way by pedestrians. Difference in volume of utilization is caused by two facts - easier and direct access from the building of railway station to southern pavement and more shops located on this side (between Hlaváčova St. and Havlíčkova St.).

Road segments are named after streets connected to selected route from the south (right). Figures are shot in direction towards the city centre (the view of pedestrian walking in appraised direction). If the figure (photo) is shot in a reverse way (towards the railway station), it is significantly marked by the names of those figures.

\subsection{Route segment main railway station - crossing with Hlaváčova Street}

This segment is consisted of the Jan Perner Sq. (area in front of the railway station) and a part of

Table 1. Cyclist transport organization on the route between the main railway station and city centre.

\begin{tabular}{|c|c|c|c|}
\hline Way for cyclist transport & Part of route & Length (m) & $\%$ of total route \\
\hline Independent cycle path (track) & Main railway station - 17 November St. & 1,035 & 59.5 \\
\hline Cyclists on traffic calmed roads & Míru and Zelenobranská St., Pernštýnské Sq. & 530 & 30.4 \\
\hline $\begin{array}{l}\text { Collective operation on pavements with } \\
\text { pedestrians }\end{array}$ & Perner Sq. and junction with Havlíčkova St. & 130 & 7.5 \\
\hline $\begin{array}{l}\text { 'Divided' path for pedestrians and cyclists - } \\
\text { lane for cyclist marked on the pavement }\end{array}$ & end of Palckého St. closer to 17 November St. & 45 & 2.6 \\
\hline
\end{tabular}


Palackého St. This segment in the whole length is located in relative rarely built-up area.

There were three possible problematic facts in front of the main railway station in the point of view of pedestrians. The first was operation of taxi cabs and possibly also of other vehicles (delivering goods to shops in hall of railway station) on the pedestrian pavement quite in front of railway station building. It was suitable for integration of different passenger transport subsystems (railway, taxi), but it was demanding on drivers of vehicles to pay attention on big number of pedestrians.

This problem disappeared in year 2017 by finalization of a complex reconstruction of the Jan Perner Sq. and by construction of a new urban public transport terminal. Taxi rank has been moved, so walking is more comfortable and safe.

Second problematic fact, which is remaining, is a frequented movement of cyclists going to stands (and tower) for bicycles located in south-eastern part of the Jan Perner Sq. These cyclists are crossing basic pedestrian route to Palackého St. (towards city centre). This intersection is not able to be replaced. New solution of infrastructure allows relative more intuitive and clearly using of it, due to raised grass areas upon the level of pavements (Fig. 6).

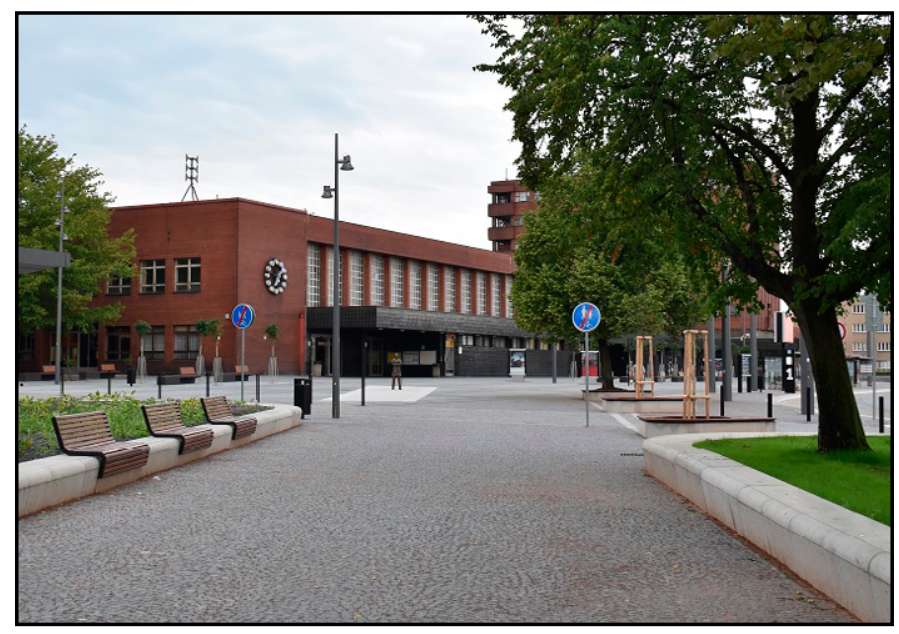

Figure 6. Reconstructed access to the railway station, Jan Perner Sq. (photo towards railway station). Source: photo authors.

The rest of this segment is copying a car road of Palackého St. Traffic on this street is relative rush, because this is a part a route I/36 as well. Route I/36 is a trunk car road in relation east-west in Pardubice. Configuration of this route segment is visible in Fig. 7.

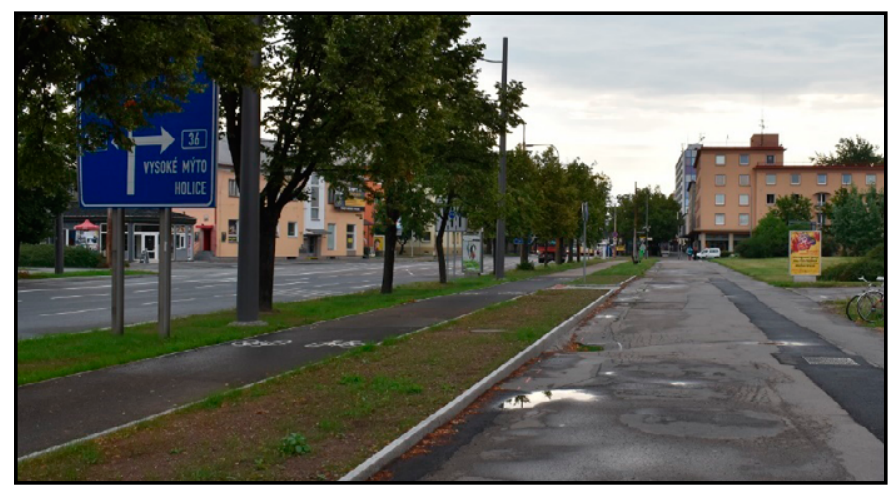

Figure 7. Route segment the main station - Hlaváčova St., a part of Palackého St.. Source: photo authors.

Basic features of this route segments are mentioned in the Tab. 2.

Table 2. Basic features of route segment the main railway station - Hlaváčova St.

\begin{tabular}{ll}
\hline Feature & Value \\
\hline Length & $310 \mathrm{~m}$ \\
Width & $6 \mathrm{~m}$ \\
Avg. speed in uncongested & $1.42 \mathrm{~m} / \mathrm{s}$ \\
situation & \\
Surface & cobblestones/asphalt \\
Cyclists & segregated lane \\
Obstacles & 0 \\
\hline
\end{tabular}

\subsection{Signalized pedestrian crossing Hlaváčova St. (named also as U Marka)}

This pedestrian crossing belongs to one of the most utilized pedestrian crossings in Pardubice. This pedestrian crossing is also equipped by crossing for cyclists. Crossing is located in Hlaváčova St. (continuation of route $\mathrm{I} / 36$ ).

Relative long interval of traffic lights and smoking of pedestrians in groups of people waiting in front the crossing in the case of red signal are problematic. On the other hand, waiting of pedestrians in front of the crossing can be more comfortable due to a bench installed here (Fig. 8).

Transport survey at this crossing was realized on Thursday 6 October 2016. 30 minutes long time frame between 18:30 and 19:00 was selected for this survey. Intensity of pedestrian traffic flow can be characterized as 'middle' (140 pedestrians/hour). It was an intent to select time frame with such intensity of traffic flow, because of possibility to register all necessary data in a detail way. 


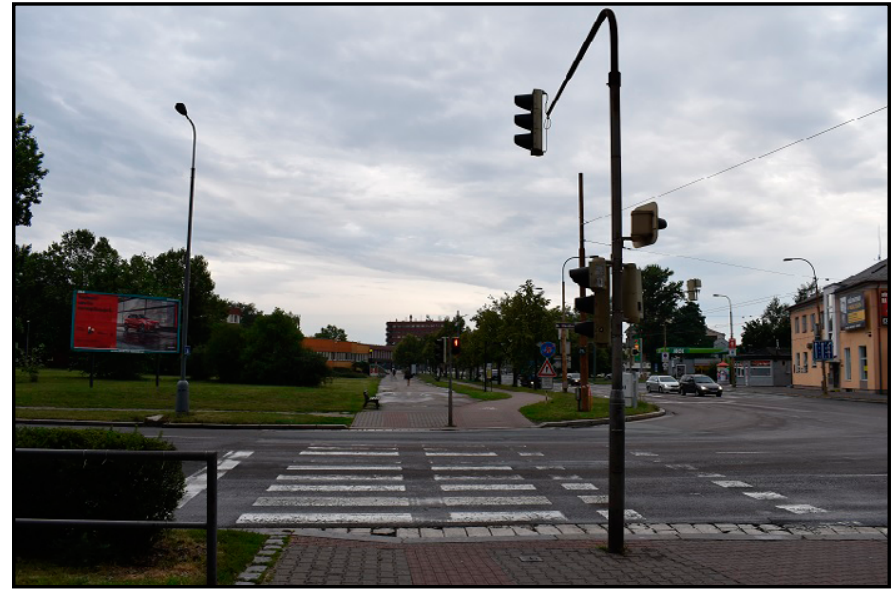

Figure 8. Signalized pedestrian crossing Hlaváčova St. (photo towards railway station). Source: photo authors.

Interval between green signals for pedestrians was irregular with average length of 100 seconds. The length of green signal is 10 seconds. Average waiting time for pedestrians walking towards the city centre was 45 seconds and towards railway station $40 \mathrm{sec}-$ onds. Overview of results is provided by the Table 3 . It can be seen on these values, that average waiting times are going to a half of duration of red signal. It can be explained in the way, that pedestrians are coming randomly and independently. Random access of pedestrians is presupposed by application of proposed modification of temporal crossing compliance rate $M T C C R$, see formula (1). Table 3 is providing additional characteristics useful for consideration of pedestrian traffic flow passing this crossing.

Two pedestrians were smoking and one listening to music by earphones. Smoking is identified as a problem at this place due to possible disturbance of other waiting pedestrians. Pedestrians using mobile phones or other electronic devices as well as pedestrian listening to music have limited possibilities to pay attention and to be orientated in traffic flow.

There was registered 'maximal' group of 30 pedestrians crossing by one green interval in the case of morning peak hours (Tuesday 11 October 2016, $7: 15-7: 45)$. Intensity of traffic flow is high, the value related to this time is 400 pedestrians/hour. This time frame can be considered as a maximal peak, because a lot of students is coming by train before 'typical' start of school education at 8:00 AM. Both surveyed intensities (peak and off-peak) are evidences, that the selected route belongs to important pedestrian routes.

Basic features of this pedestrian crossing (U Marka) are mentioned in the Tab. 4.

Table 4. Basic features of pedestrian crossing Hlaváčova St. ('U Marka')

\begin{tabular}{lc}
\hline Feature & Value \\
\hline Length of crossing & $14 \mathrm{~m}$ \\
Width of crossing & $4 \mathrm{~m}$ \\
Car lanes & 4 \\
Signalization & yes \\
Buttons for pedestrians & no \\
Avg. duration of signaling cycle & $100 \mathrm{~s}$ \\
Avg. duration of green signal 'WALK' & $10 \mathrm{~s}$ \\
Modified temporal crossing compliance rate & 0.100 \\
(MTCCR) & \\
Crossing for cyclists & yes \\
\hline
\end{tabular}

Passenger coming to Pardubice central bus station can get connected to appraised pedestrian route at this place.

\subsection{Route segment crossing with Hlaváčova Street - crossing with Macanova Street}

Appraised pedestrian route is coming into built-up area of the CBD by this segment (Fig. 9). This seg-

Table 3. Transport survey at the pedestrian crossing 'U Marka', 6 October 2016, 18:30 - 19:00.

\begin{tabular}{lcc}
\hline Way for cyclist transport & Direction city & Direction railway station \\
\hline Pedestrians (total numbers) & 29 & 44 \\
Pedestrians using mobile phone or other electronic device & 2 & 5 \\
(pedestrians from above mentioned numbers) & & $34 \mathrm{~s}$ \\
Average interval between arrivals of pedestrians & $55 \mathrm{~s}$ & 3 \\
Cyclists & 5 & $446 \mathrm{~s}$ \\
Average interval between arrivals of cyclists & $354 \mathrm{~s}$ & \\
\hline
\end{tabular}


ment belongs also to Palackého St., but route I/36 is diverted now to Hlaváčova St. and the car traffic has city character (transit and freight transport are quite reduced here). Street is also important for urban and regional bus public transport. This segment is interesting by relative high number of obstacles for pedestrians created especially by mobile advertising stands of shops. There is the highest density of obstacles from all the surveyed route segments $(2.33 \mathrm{ob}-$ stacles $/ 50 \mathrm{~m}$ ).

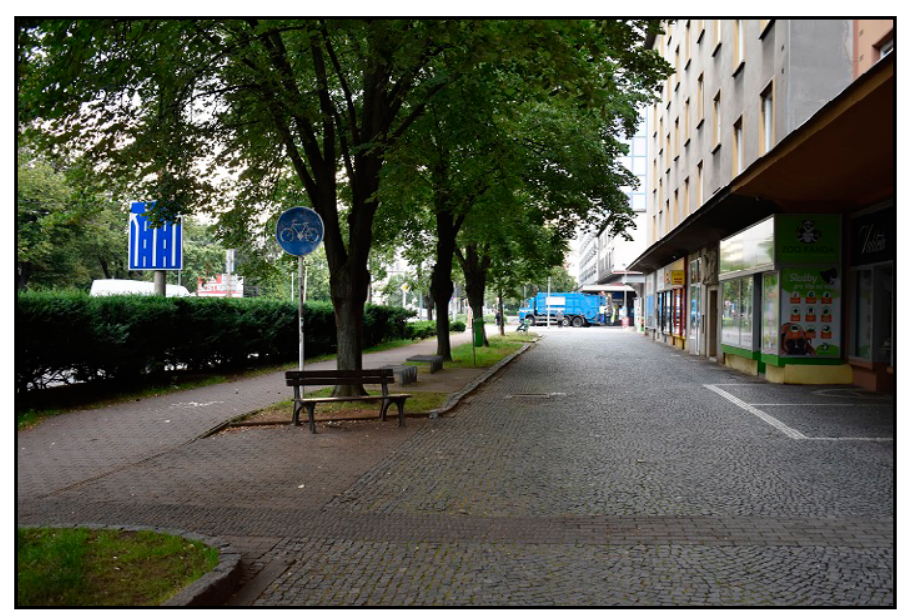

Figure 9. Route segment Hlaváčova St. - Macanova St. Source: photo authors.

Basic features of this route segment are mentioned in the Tab. 5.

Table 5. Basic features of route segment Hlaváčova St. Macanova St.

\begin{tabular}{ll}
\hline Feature & Value \\
\hline Length & $150 \mathrm{~m}$ \\
Width & $6 \mathrm{~m}$ \\
$\begin{array}{l}\text { Avg. speed in uncongested } \\
\text { situation }\end{array}$ & $1.47 \mathrm{~m} / \mathrm{s}$ \\
Surface & cobblestones \\
Cyclists & segregated lane \\
Obstacles & 7 in total; 2.33 per $50 \mathrm{~m}$ \\
\hline
\end{tabular}

\subsection{Not signalized pedestrian crossing Macanova St.}

Macanova St. is used especially by local traffic with origin or destination in south-west part of the CBD. Number of block of flats is located in this area. This street, incl. a pedestrian crossing, is newly reconstructed. The pedestrian crossing is divided into 2 parts for each direction of car drive since this reconstruction (Fig. 10). Pedestrian crossing is equipped by a crossing for cyclists.

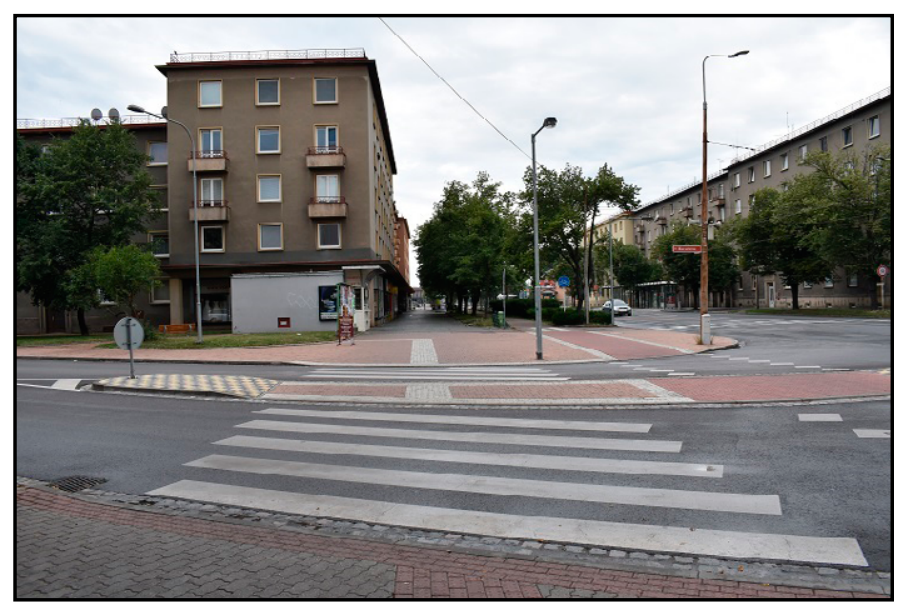

Figure 10. Not signalized pedestrian crossing Macanova St. (photo towards railway station). Source: photo authors.

Basic features of this pedestrian crossing are mentioned in the Tab. 6 .

Table 6. Basic features of pedestrian crossing Macanova St.

\begin{tabular}{ll}
\hline Feature & Value \\
\hline Length of crossing & $14 \mathrm{~m}$ (2 parts, each $5 \mathrm{~m})$ \\
Width of crossing & $4 \mathrm{~m}$ \\
Car lanes & 2 \\
Signalization & no \\
Crossing for cyclists & yes \\
\hline
\end{tabular}

\subsection{Route segment Macanova St. - Havlíčkova St.}

This route is similar like the segment between Hlaváčova and Macanova St. Difference is in the fact, that this segment is created by 2 blocks of flats. The surface is asphalt in front of the first block of flats and cobblestones in front of the second block of flats. An advantage is that the first part is partially covered by a block of flats, that pedestrians can be partially protected against rain (Fig. 11).

Basic features of this route segment are mentioned in the Tab. 7. 


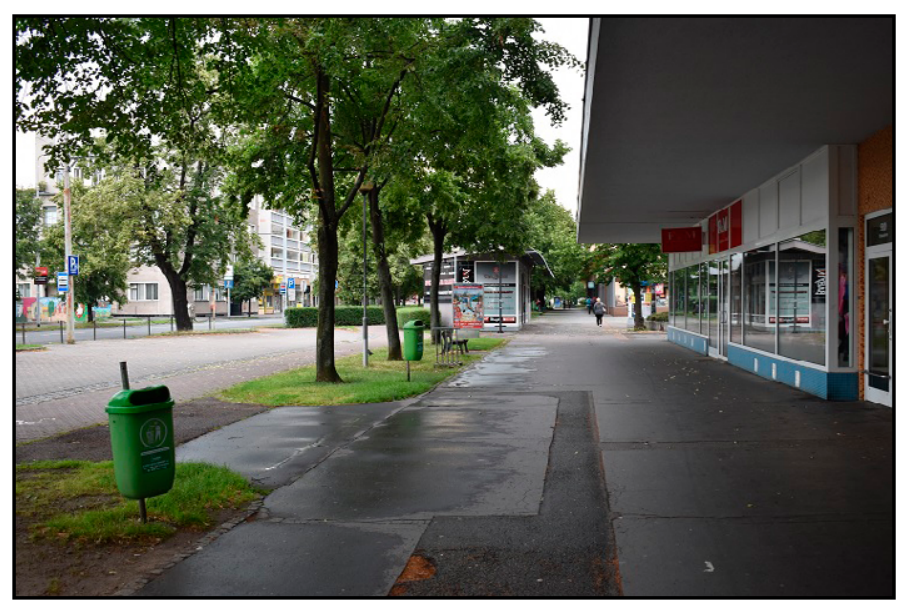

Figure 11. Route segment Macanova St. - Havlíčkova St. Source: photo authors.

Table 7. Basic features of route segment Macanova St. junction of Palackého and Havlíćkova St.

\begin{tabular}{ll}
\hline Feature & Value \\
\hline Length & $275 \mathrm{~m}$ \\
Width & $6 \mathrm{~m}$ \\
$\begin{array}{l}\text { Avg. speed in uncongested } \\
\text { situation }\end{array}$ & $1.46 \mathrm{~m} / \mathrm{s}$ \\
Surface & asphalt/cobblestones \\
Cyclists & segregated lane \\
Obstacles & 2 in total; 0.36 per $50 \mathrm{~m}$ \\
\hline
\end{tabular}

\subsection{Intersection of Palackého St. and Havlíčkova St.}

There is $20 \mathrm{~m}$ long area where the pedestrian route, incl. cycle track is interrupted by a little square. Pedestrian as well as cyclist flows of different directions are crossing here (Fig. 12). This junction needs a thoughtfulness of all participants of transport operation due to crossing of flows in different directions.

Crossing of cycle track with pedestrian pavements ensuring accessibility to the urban public transport stop Palackého is other problem. There are limited conditions to view for cyclists as well as for pedestrians due to vegetation, so that possible conflicts can be occurred.

\subsection{Route segment Havlíčkova St. - 17 November St.}

This route segment can be divided into two parts. The first is similar like two previously mentioned street segments (Fig. 13), but with smaller density of shopping facilities located on the southern (right) side. The second part (Fig. 14) is a pavement copying a block of flats with shops located in ground and first floors. Pedestrians are also partially protected against rain by a 'shopping balcony' in the first floor of this block of flats. Pavement in this part is equipped by a lane for cyclists. This lane for cyclists is marked on a pavement (by vertical and horizontal traffic signs) and it is $45 \mathrm{~m}$ long only (Fig. 14). This can be a problem, because pedestrians are often entering this path for cyclists. Pedestrian flows are relative intensive and dense at this place.

Basic features of this route segment are mentioned in the Tab. 8.

Part of segment with lane for cyclists marked at pavement close to the junction with 17 November street is in the Fig. 14.

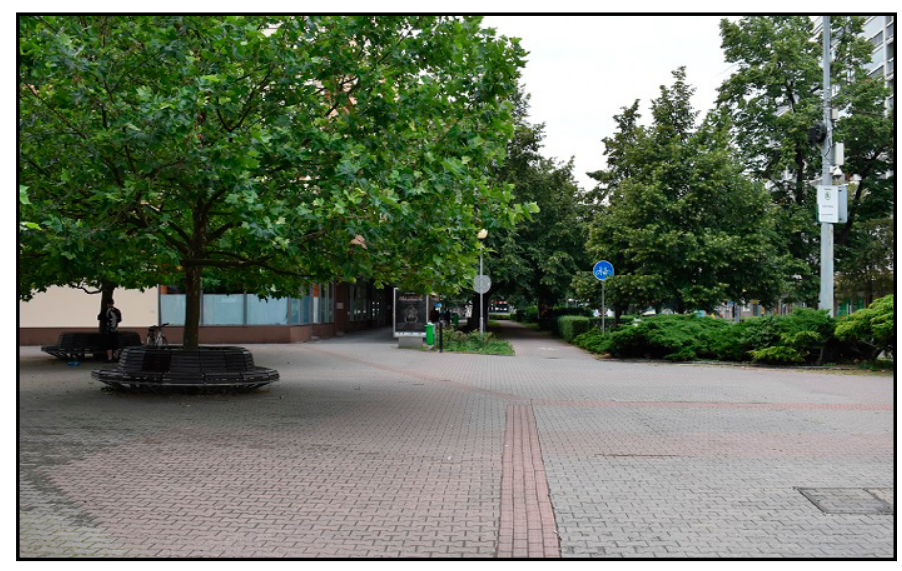

Figure 12. Intersection of Palackého St. and Havlíčkova St. (photo towards railway station). Source: photo authors.

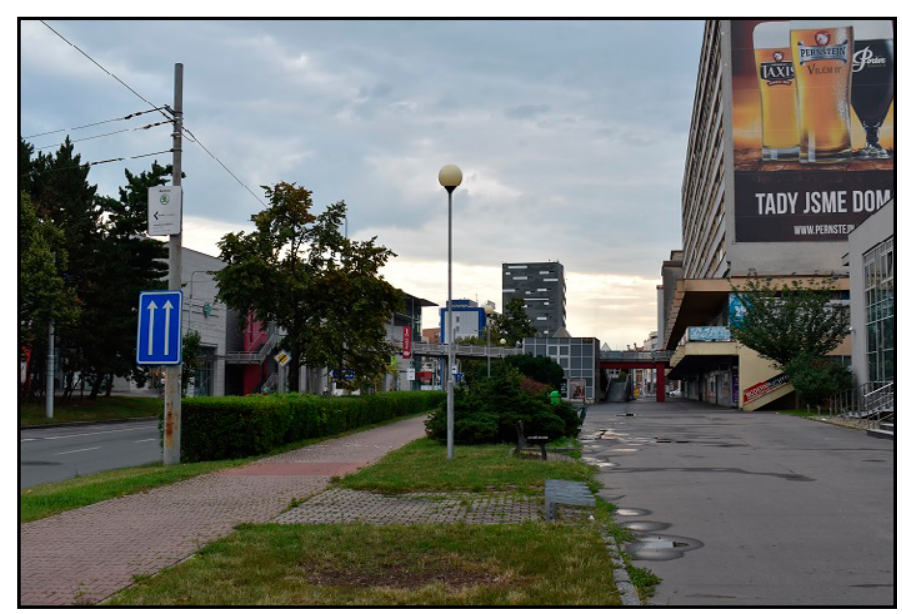

Figure 13. Route segment Havlićčkova St. 17 November St., the $1^{\text {st }}$ part. Source: photo authors. 
Table 8. Basic features of route segment Havlíčkova St. 17 November St.

\begin{tabular}{ll}
\hline Feature & Value \\
\hline Length & $230 \mathrm{~m}$ \\
Width & $7 \mathrm{~m}$ \\
$\begin{array}{l}\text { Avg. speed in uncongested } \\
\text { situation }\end{array}$ & $1.45 \mathrm{~m} / \mathrm{s}$ \\
Surface & asphalt \\
Cyclists & segregated lane, $45 \mathrm{~m}$ a lane \\
& for cyclist on pavement \\
Obstacles & 4 in total; 0.87 per $50 \mathrm{~m}$ \\
\hline
\end{tabular}

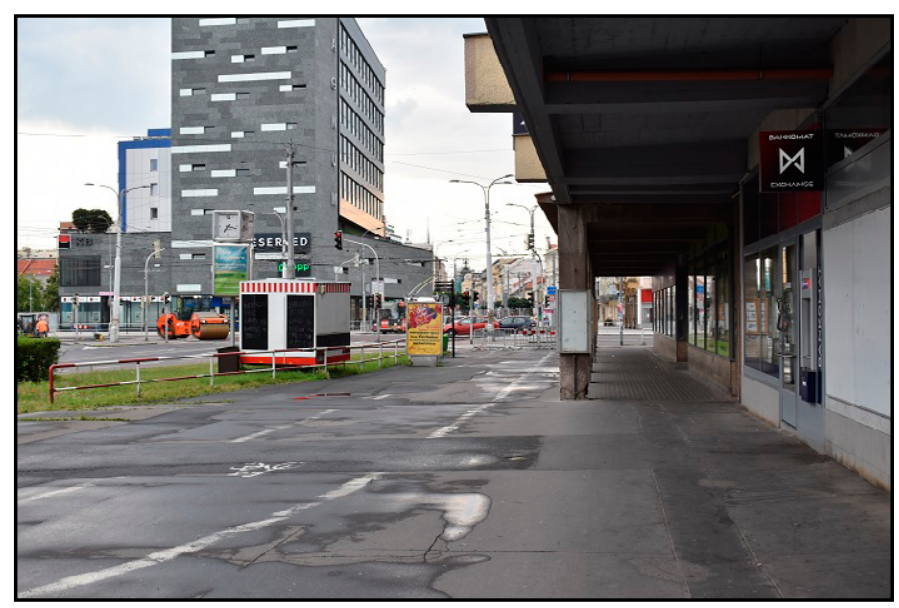

Figure 14. Route segment Havlíčkova St. - 17 November St., the $2^{\text {nd }}$ part equipped by the lane for cyclists. Source: photo authors.

\subsection{Junction of Palackého St. and 17. listopadu St. (a set of 3 pedestrian crossings at one junction)}

Signalized junction of streets Palackého, Míru, 17 November and Masaryk Sq. is a junction of two main roads of the CBD. Pedestrian route from the main railway station to the city centre is crossing the 17 November street by a set of 3 subsequent pedestrian crossings. First two are signalized, the third not. The third crossing is over the road connected to a pedestrian zone and used especially by limited number of trolleybuses only. This set of pedestrian crossings is in the Fig. 15.

Basic features of this set of 3 pedestrian crossings are mentioned in the Tab. 9. Crossings are numbered in order from the main railway station to the city centre (crossing No. 1 is located in forefront in the Fig. 15, crossing No. 3 in forefront in the Fig. 16).

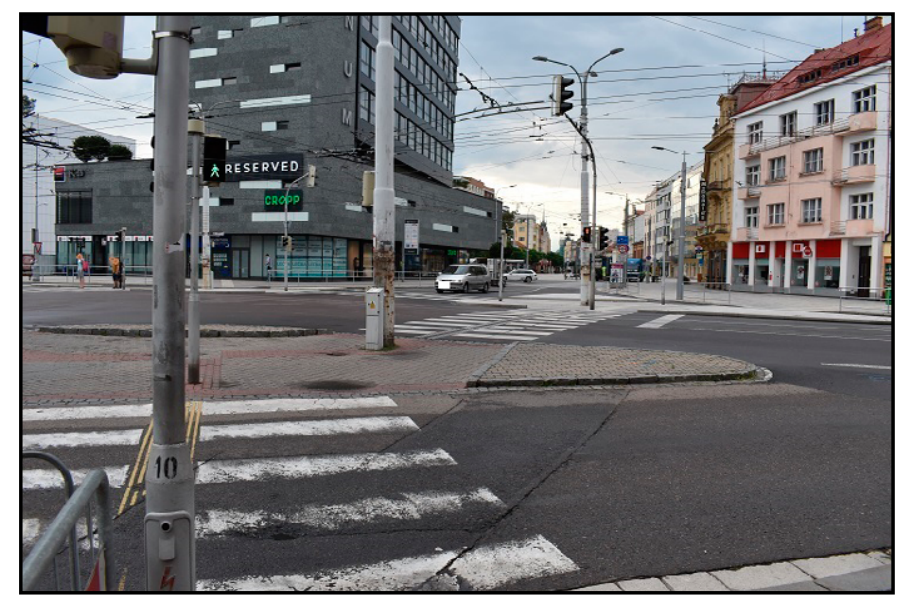

Figure 15. Set of 3 pedestrian crossings (17 November St.) Source: photo authors.

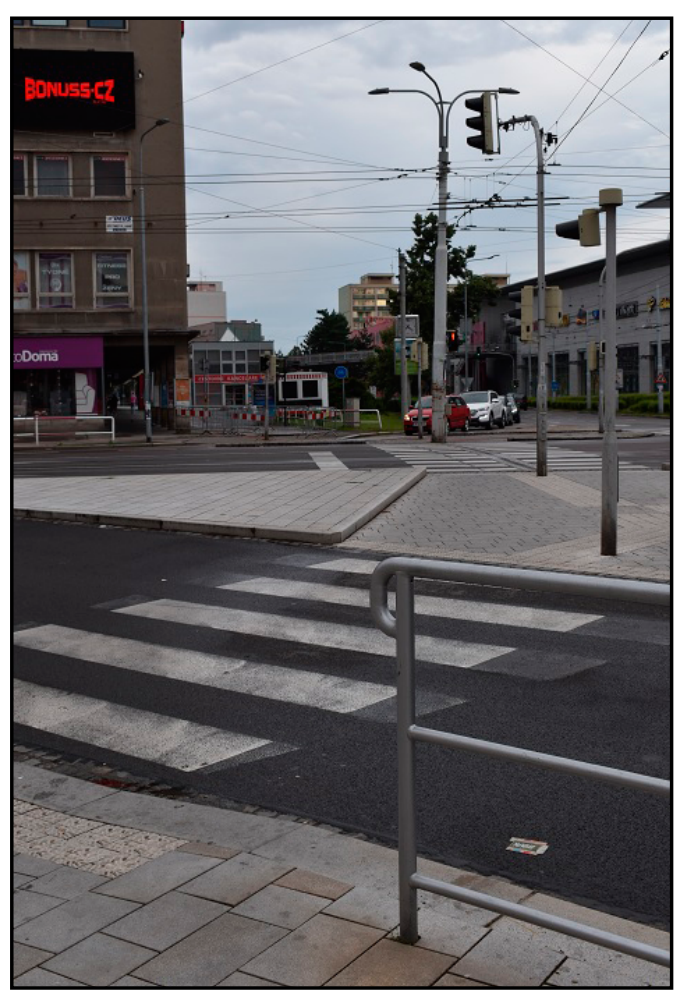

Figure 16. Set of 3 pedestrian crossings (17 November St.), reverse view towards railway station. Source: photo authors.

Pedestrians walking towards the city centre will wait between signalized crossings No. 1 and No. 2 for 7 seconds, in other direction towards railway station for 30 seconds.

\subsection{Route segments located in Míru St. (tř. Míru)}

Míru St. is $510 \mathrm{~m}$ long. This street has been changed into a pedestrian zone with limited operation of trolleybuses (or other vehicles). Cyclists can use this street without any restrictions. This street is divided into 3 route segments by Sladkovského and Jindřišská 
Table 9. Basic features of the set of 3 pedestrian crossings -17 November St

\begin{tabular}{lccc}
\hline Feature & Crossing No. 1 & Crossing No. 2 & Crossing No.3 \\
\hline Length of crossing & $5 \mathrm{~m}$ & $11 \mathrm{~m}$ & $5 \mathrm{~m}$ \\
Width of crossing & $5 \mathrm{~m}$ & $5 \mathrm{~m}$ & $3 \mathrm{~m}$ \\
Car lanes & 1 & 3 & 1 \\
Signalization & yes & yes & no \\
Buttons for pedestrians & no & no & - \\
Avg. duration of signaling cycle & $87 \mathrm{~s}$ & $87 \mathrm{~s}$ & - \\
Avg. duration of green signal 'WALK' & $42 \mathrm{~s}$ & $6 \mathrm{~s}$ & - \\
Modified temporal crossing compliance rate (MTCCR) & 0.483 & 0.069 & - \\
Crossing for cyclists & no & no & no \\
\hline
\end{tabular}

St. branching to the south (right) in the point of this appraisal. On the other hand, the first two segments have the same conception - it is a pedestrian shopping street by relative width pavements and relative narrow road (for trolleybuses, cyclists and cars with permission only). Cars supplying shops or other objects can enter in limited time frame only. Pavements and the road are on the same level, so that no raised kerbs are used here. This solution allows pedestrian flows to use also the route (if a trolleybus is not going). The way of operation is illustrated by Fig. 17 .

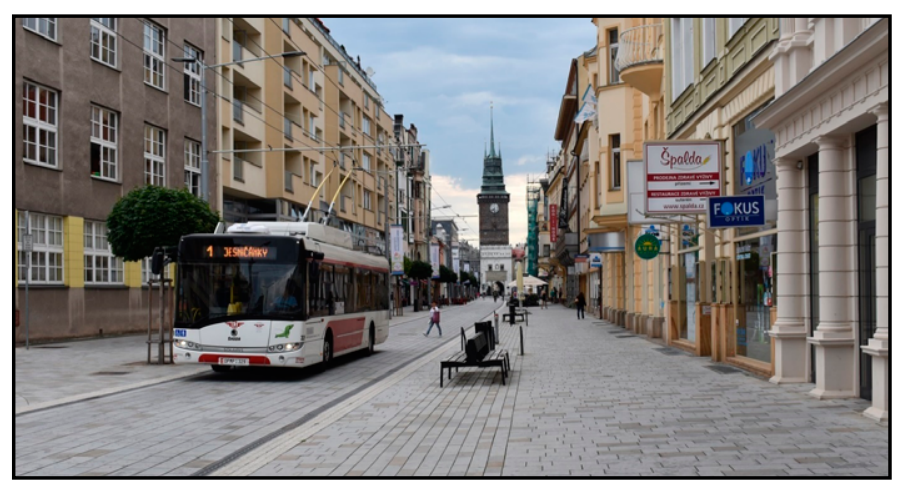

Figure 17. Traffic organization in Míru St. (middle route segment Sladkovského St. - Jindřišská St.). Source: photo authors.

The first segment is not marked as a pedestrian zone, but as a living zone in formal point of view. This zone is allowing access of cars, but speed is reduced. On the other hand, living area is equipped by a set of additional restrictions to drive here. Practically, people are considering the whole Míru St. as a pedestrian zone, where road traffic is calmed. Pedestrians are used to pay attention and to make a place for possible car moving especially in outer parts of Míru St.. Last place, where car operation is possible, is the intersection with Sladkovského St. Sladkovského St. is operated in one-way regime in southern part. This operation is not seen as a problem. Full replacement of all car operation of this area will be ideal, but it is not possible to be realized due to accessibility of other streets in surroundings with no other appropriate connection to other road network of the city.

The width of southern pavement is approximately $7 \mathrm{~m}$ in first two route segments bordered by streets 17 November St., Sladkovského St. and Jindřišská St. The last route segment in Míru St. between Jindřišská St. and Sq. of Republichas 4 m wide southern pavement due to position of buildings closer to the axis of Míru St. It has one important consequence for pedestrians. There is a stripe between pavement and route equipped by benches, litter bins, bicycle stands, advertising panels and bus stop shelters as well (Fig. 17) in the case of wider pavements. Outside seating areas of restaurants are located at pavements as well in all three route segments in Míru St. (including the narrow one). On the other hand, these potential obstacles in walking can not be considered as a serious problem, because they contribute to a character of this place (this street is considered as city promenade). Obstacles can be easy overpassed due to possibility to walk on a route.

One notice can be added to a trolleybus traffic operated here. There were long discussions, if this transport should be operated in this street (pedestrian zone) or not. Compromise solution has been made. The infrastructure remains here, but the traffic is calmed. Only 4 trolleybuses per hour are going in this street now - summer 2017. DPMP, (2017). Pos- 
sible disturbing effects felt by pedestrians are minimized. The other trolleybuses (of other lines) are going around in Sukova St.

The most important fact of this is not too much accented. This infrastructure in Míru St. can be used also by diverted buses (lines) in the case of a traffic accident, closure or other situation making heavy loaded Sukova St. or Masaryk Sq. unpassable. This is helpful to an operational stability of urban public transport, because possible bottlenecks can be overpassed. There is not any other trolleybus route in direction west-east (in spite of Míru St. and Sukova St.). Irregular operation of Line No. 1 here, documented in Fig. 17, is an evidence of this advantage. Second advantage is, that it is possible to terminate and turn-back the vehicles (advantage especially for irregular situations) here, directly in the CBD.

This can be also an important argument by decision making about public transport infrastructure on pedestrian zones. It can be recommended to take into account configuration of the whole trolleybus network (or tram network as well in other cities) and the possibilities to bypassing, overtaking or turning of vehicles.

Basic features of all three route segments in Míru St. are mentioned in the Tab. 9.

\subsection{Places for crossing located in Míru St.}

It is necessary to cross three roads by passing on appraised pedestrian route in the locality of Míru St. These crossings are marked as place for crossing (not a zebra-crossing). The first is Sladkovského St. (Fig. 18). This street is used especially by cars accessing Sladkovského St. in direction from north to south. This traffic is almost local, terminating in the areas located southern of Míru St. The length of the crossing is $6 \mathrm{~m}$.

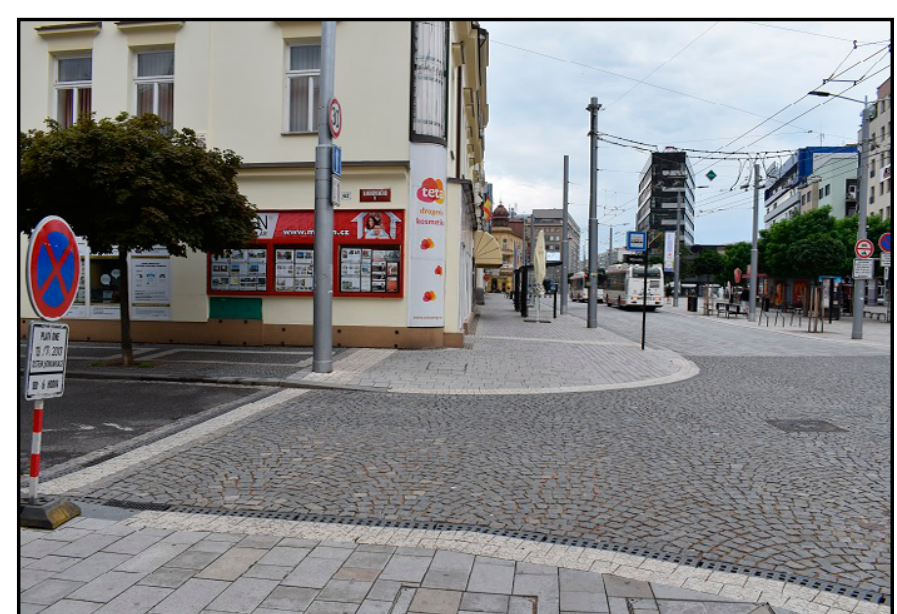

Figure 18. Place for crossing Sladkovského St. (photo towards railway station). Source: photo authors.

The second street needed to be crossed is Jindřišská St. (Fig. 19). This street is accompanying car traffic from neighbouring area to Míru St. These cars are continuing towards the Sq. of Republic. The volume of this traffic is no problem at the place for crossing. The length of the crossing is $6 \mathrm{~m}$.

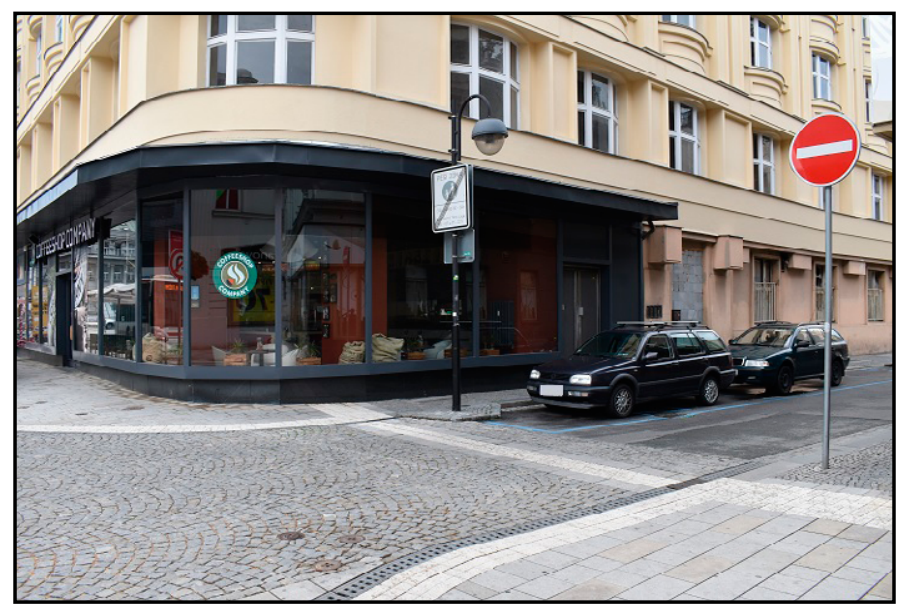

Figure 19. Place for crossing Jindřišská St. Source: photo authors.

Table 9. Basic features of route segments in Míru St.

\begin{tabular}{llll}
\hline Feature & $\begin{array}{l}\text { 17 November St. } \\
\text { Sladkovského St. }\end{array}$ & $\begin{array}{l}\text { Sladkovského St. }- \\
\text { Jindřišská St. }\end{array}$ & $\begin{array}{l}\text { Jindřišská St. }- \\
\text { Sq. of Republic }\end{array}$ \\
\hline Length & $200 \mathrm{~m}$ & $235 \mathrm{~m}$ & $75 \mathrm{~m}$ \\
Width & $7 \mathrm{~m}$ & $7 \mathrm{~m}$ & $4 \mathrm{~m}$ \\
Avg. speed in uncongested situation & $1.31 \mathrm{~m} / \mathrm{s}$ & $1.40 \mathrm{~m} / \mathrm{s}$ & $1.39 \mathrm{~m} / \mathrm{s}$ \\
Surface & paving & paving & paving \\
Cyclists & on the route & on the route & on route \\
Obstacles & Not registered, able to be overtaken by using of route. &
\end{tabular}


The last place for crossing is the road of Míru St. itself (Fig. 20) with width of $7 \mathrm{~m}$. Signalized pedestrian crossing at the Sq. of Republic (mentioned in also in chapter 6.2.) is located on the left side of Míru St. Crossing on the right side is not possible.

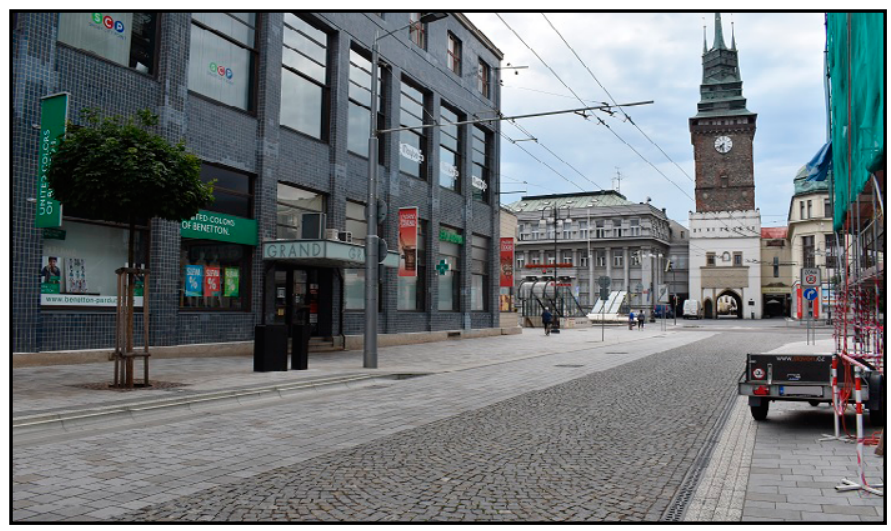

Figure 20. Place for crossing Míru St. Source: photo authors.

\subsection{Signalized pedestrian crossing Sq. of Republic}

Characteristics of this signalized pedestrian crossing are taking a part of the chapter 6.2. It is described as an individual locality there (questions of closed underpass and of escalators in underpass).

Basic features of this pedestrian crossing are mentioned also in the Tab. 10. It is placed here for a systematic approach to whole line from the main railway station to the city centre (Pernštýnské Sq.). This pedestrian crossing is only one on the appraised route, which is signalized independently (not belongs to any signalized junction), but it is also close to the junction Míru St. - Sq. of Republic (for details please see the chapter 6.2.). It is also only one signalized pedestrian crossing with application on buttons for pedestrians. It is also an evidence that this route is used by many pedestrians, because application of buttons for pedestrians (and operation of pedestrian crossing signalization 'on request') is common at a lot of other signalized crossings in Pardubice out of this appraised route.

Table 10. Basic features of pedestrian crossing Sq. of Republic

\begin{tabular}{ll}
\hline Feature & Value \\
\hline Length of crossing & $16 \mathrm{~m}$ \\
Width of crossing & $5 \mathrm{~m}$
\end{tabular}

Car lanes 4

Signalization

yes

Buttons for pedestrians

yes

Avg. duration of signaling cycle

$90 \mathrm{~s}$

Avg. duration of green signal 'WALK'

$8 \mathrm{~s}$

Modified temporal crossing

0.089

compliance rate (MTCCR)

Crossing for cyclists

no

\subsection{Route segment Sq. of Republic - Pernštýnské Sq. (Zelenobranská St.)}

The last segment of the appraised route between the main railway station and the city center (historical square) is led through the Green Gate (a historical city gate with tower, visible in the Fig. 20) and in Zelenobranská St. The way under a gate is fully pedestrianized. The Zelenobranská St. (35 m long) is equipped by a car road like a historical Pernštýnské Sq. Car access to the west part of Pernštýnské Sq. and to Zelenobranská St. is restricted. Cars with permission and cars supplying of shops etc. can enter this area in given time frame only. The volume of traffic is too low due to this restriction (and a limited number of destinations in this street). There are not usually any problems occurring in practice, but not-presupposed meeting of pedestrians with a car is theoretically possible here.

Pedestrians can possibly invite a pedestrian zone (according to experiences from similar historical places of other cities) and meeting with a car can be 'surprising'. On the other hand, approaching speed of a car will be low. There is usually placed an outside seating area of a restaurant close to the road, so that a car driver will go slowly and possibly stop. It is not able to be characterized as a problem, car traffic is clamed.

Table 11. Basic features of route segment Sq. of Republic - Pernštýnské Sq. (Zelenobranská St.)

\begin{tabular}{ll}
\hline Feature & Value \\
\hline Length & $105 \mathrm{~m}$ \\
Width & $6 \mathrm{~m}$ \\
Avg. speed in uncongested & $1.33 \mathrm{~m} / \mathrm{s}$ \\
situation & \\
Surface & cobblestones \\
Cyclists & together with pedestrians \\
Obstacles & 4 in total; 1.90 per $50 \mathrm{~m}$ \\
\hline
\end{tabular}




\subsection{Appraisal of the whole pedestrian route (line)}

Limit values based on research of Soni et al., (2016) and Wicramasinghe et al., (2017) will be applied for general appraisal of this pedestrian route in whole length.

\section{a) Width of pavements}

Limit values for pavement width are defined by Wicramasinghe et al., (2017) in this way: the best (level 1) are the values of pavement width $>2 \mathrm{~m}$, the middle (level 2) values $1-2 \mathrm{~m}$, the bad (level 3 ) values $<1 \mathrm{~m}$. The narrowest pavement appraised on selected route has width of $4 \mathrm{~m}$, the others $6-7 \mathrm{~m}$. The worst value is two times higher than the limit for the best level 1. Other values of width are minimally three times higher. It can be told, that all route is fully satisfying in this point of view and prepared for intensive pedestrian flows.

Width of pavements is no problem, can be told also in the point of view of practice. Problems in this field are occurring sometimes, when a huge group of pedestrians is cumulated in front of signalized crossing (waiting for a green signal) in peak times. This effect is occurred at all of 4 signalized crossing at this route. The solution can be shortening of time interval between green signals for pedestrians, but this measure can have negative consequences on road traffic (car traffic peaks are usually corresponding to pedestrian traffic peaks).

Pedestrians are 'organized' by a traffic sign C 14a 'Pedestrians, walk on right' on the signalized pedestrian crossing located in the Sq. of Republic. It is due to high volume of crossing pedestrians. The aim is to prevent conflicts of pedestrians on the crossing.

\section{b) Average pedestrian speed in 'uncongested' situation}

Limits for pedestrian speeds are mentioned by Soni et al., (2016), Limits are divided into 6 categories and they are marked by letters from A to F. Average speed $V>1.30 \mathrm{~m} / \mathrm{s}$ is a limit for the best category A. Limit for the worst category F is $V \leq 0.75 \mathrm{~m} / \mathrm{s}$. All of surveyed route segments belong to the best category $\mathrm{A}$.

The route segment with an average speed closest to the limit is the segment located on Míru St. between 17 November St. and Sladkovského St. $(V=1.31 \mathrm{~m} / \mathrm{s})$.

Average speed on the whole route (times for route crossings are omitted for this purpose) is $1.41 \mathrm{~m} / \mathrm{s}$ and belongs to the category A. In spite of the fact, that average speed can be decreased in peak hours, it can be told, that this route is satisfying in the point of view of average speed.

\section{c) Number of obstacles}

Limits for numbers of obstacles are defined by Wicramashinge et al., (2017) as expression by number of obstacles per $50 \mathrm{~m}$ of route. The best level 1 is 0 (no obstacle), middle level 2 is defined by an interval of values $(0 ; 5)$ and the worst level 3 by more than 5 obstacles per $50 \mathrm{~m}$.

In the best level 1 is the first route segment between the main railway station and Hlaváčova St. with no obstacles identified.

All other segments are evaluated by the value related to the middle level 2 . The worst route segment is between Hlaváčova St. and Macanova St. with 2.33 obstacles per $50 \mathrm{~m}$. It is caused by a relative high number of advertising stands in front of shops (registered in by survey).

Number of obstacles was not surveyed at Míru St. due to possibility to use the whole area of street for walking (in the most of this street).

Surface is suitable, the route is undergoing reconstruction works in 'step by step' regime. This approach is adequate and suitable. The Jan Perner Sq., Macanova St. and Míru St. were reconstructed before a short time.

Second important fact on this pedestrian route are pedestrian crossings. Signalized, not signalized zebra-crossings are used as well as places for crossing. This configuration is suitable and corresponding with the transport meaning (traffic load) of each crossed street.

The most compliant signalized pedestrian crossing is crossing on the car lane connecting Palackého St. and 17 November St. at the junction of Palackého St. x 17 November St. x Míru St. x Masaryk Sq. according to the modified temporal crossing compliance rate calculated by the formula (1) and based on Sisiopiku et al., (2003).

The MTCCR $=0.483$ in this case. Values of $M T C C R \leq 0.100$ are occurred at all other surveyed signalized pedestrian crossings.

Width of all pedestrian crossings is in consonance with the Czech technical standard No. ČSN 73 6110:2010 Design of Urban Roads ČSN 73 6110:2010, (2010). The so called reduced width of $3 \mathrm{~m}$ is applied at pedestrian crossing No. 3 at 17 November St. Minimal width of $4 \mathrm{~m}$ is kept in all the cases. These crossings are wider. 
Contemplation of possible measures:

Due to the fact, that the most of results of this appraisal are satisfying, there is not too much space for 'energic' measures. On the other hand, it is necessary to maintain this relative good level of quality very carefully and to not admit worsening of this state. On the other hand, some recommendations can be possible found there. Relative good fulfilling of quality indices is not a reason to stop activities leading to improvement of conditions for pedestrians traffic.

These recommendations can be used also in other cities are due to its general form to:

- take care about pedestrian infrastructure condition, to do necessary maintenance and reconstruction works,

- reflect all technical standards by reconstruction of state-of-art or by construction of a new infrastructure,

- survey the stand in pedestrian transport regularly, to identify and solve possibly occurred problems (it can be partially inspired also by the way of appraisal presented in this paper),

- take care about sensible and intuitive marking by traffic signs,

- be sense to other effects like smoking of pedestrians in front of crossing, danger to be poured by water from puddles, to ensure a good condition to view over vegetation etc.,

- enforce correct utilization of traffic infrastructure,

- make motivation public campaigns explaining correct and also mistaken using of infrastructure, if necessary,

- motivate pedestrians and also other transport participants to thoughtfulness,

- try to minimize the number of possible obstacles on pedestrian routes,

- consider possible replacement of urban public transport infrastructure by pedestrianization (making of pedestrian zones) in the scope of whole urban public transport network as well.

\section{CONCLUSIONS}

Conclusion parts of papers will be usually dedicated to final recommendations. It is not necessary to re- peat all recommendations in this paper, because all recommendations are presented on a relative large space in previous chapters in individual contexts of all mentioned problems. General summary is made here only due to this.

The aim of this paper is to appraise conditions for pedestrian transport (in the case of the city Pardubice). This aim has been fulfilled by this paper.

Three problematical localities in the point of view of pedestrian transport were analysed, each of those localities represents a different problem in pedestrian transport:

- placement of a rush urban transport interchanging node in a rush street and related problems by crossing of this route by interchanging passengers,

- preferences to using level pedestrian crossing or underpass, equipment of underpass by escalators,

- conflict situation between pedestrians and cyclists in narrow spaces (on divided path for pedestrians and cyclists), incl. question of correct, sense, clear and intuitive using of traffic marking and traffic signs.

Each locality and related problem is characterized (surveyed or documented) and proposals of possible measures for the city of Pardubice and for other cities are significantly presented in adequate part of the paper.

Conditions for walking in the city are analysed by an appraisal of pedestrian route connecting the main railway station and the main (historical) Pernštýnské Square in the city centre. This route is frequently used by pedestrians also for the fact that it is a main route in the $\mathrm{CBD}$.

Individual route segments and pedestrian crossings located on this route are considered independently. Applied procedures are based on methods presented by Sisiopiku et al., (2003), Soni et al., (2016) and Wicramashinge et al., (2017).

The result of the appraisal is, that the most of observed characteristics are fulfilled in a satisfying way in the case of appraised route. Some general measures for improvement of pedestrians' conditions are mentioned in the chapter 7.14. of this paper. Presented analysis can be used as a background (theoretical base) for appraising of other pedestrian routes (e.g. in other cities) as well. 


\section{REFERENCES}

AUSSERER, K., FÜSSL, E., RISSER, R.: NutzerInnenbefragung: Was gefällt am Gehen und was hält davon ab? Endbericht. Wien: FACTUM Chaloupka \& Risser OG im Auftrag der Magistratsabteilung 18 - Stadtentwicklung und Stadtplanung, 2013. https://www.wien.gv.at/stadtentwicklung/studien/pdf/ b008356.pdf

BROŽOVÁ, P., BULÍČEK, J., HRUBAN, I.: Changes in Pedestrian and Cyclist Transport on Pardubice's Masaryk Square Caused by Urbanistic Development of City Centre. $6^{\text {th }}$ International Scientific Conference - Conference Proceedings, University of Pardubice, 3.-4.9.2015, p. 43 - 59, ISBN 978-80-7395924-1.http://isc.upce.cz/index_en.html

BULÍČEK, J., BROŽOVÁ, P., HRUBAN, I., ŠUCHA, M.: Interakce cyklistů a chodcũ ve společném prostoru ve městě Pardubice. Psychologie a její kontexty, 2014, roč. 2014, č. 5 (suppl.2014), s. 63-88. http://psychkont.osu.cz/archiv/5-S-2014.htm

COST 358 Rob Methorst, Hector Monterde i Bort, Ralf Risser, Daniel Sauter, Cheltenham: WALK21 ISBN: 978-0-9566903-0-2.

Miles Tight and Jim Walker- PQN Final Report.

ČSN 73 6110:2010, 2010. Design of urban roads. Czech technical standard.

DPMP, 2017. Dopravní podnik města Pardubic, a.s. online [cited 2017-07-25], www.dpmp.cz

FÜSSL, E., HAUPT, J. 2017. Understanding cyclist identity and related interaction strategies. A novel approach to traffic research. Transportation Research Part F, 46, 2017, 329-341, http://dx.doi.org/10.1016/j.trf.2016.08.003

DHANANI, A., TARKHANYAN, L., VAUGHAN, L. 2017. Estimating pedestrian demand for active transport evaluation and planning. Transportation Research Part A, 103, 2017, 54-69, http://dx.doi.org/10.1016/j.tra.2017.05.020

HARIYONO, J., JO, K.H. 2017. Detection of pedestrian crossing road: A study on pedestrian pose recognition. Neurocomputing, 234, 2017, 144-153, http://dx.doi.org/10.1016/j.neurocom.2016.12.050

KOŠŤÁLOVÁ, J., MATUŠKA, J. 2016. Save guiding of visually impaired people - artificial guiding lines arrangements in the infrastructure. In Proceeding of International Conferences on Traffic and Transport Engineering, Belgrade, 24. - 25. 11. 2016. p. 1073-1080. ISBN 978-86-916153-3-8. http://hdl.handle. net/10195/67378

ORTÚZAR, J.D., WILLUMSEN, L.G. Modelling Transport Third Edition. Chichester : John Wiley \& Sons, c2001, 499 p., ISBN 0-471-86110-3.

PÖSCHL, D. - TÝFA, L.: Simulační modely pěších proudů. Perner's Contacts, č. 1, 2011, roč. 6. http://pernerscontacts. upce.cz/21_2011/Poschl.pdf

RANKAVAT, S., TIWARI, G. 2016. Pedestrian perceptions for utilization of pedestrian facilities - Delhi, India. Transportation Research Part F, 42, 2016, 495-499, http://dx.doi. org/10.1016/j.trf.2016.02.005
RÄSÄNEN, M., LAJUNEN, T., ALTICAFARBAY, F., AYDIN, C. 2007. Pedestrian self-reports of factors influencing the use of pedestrian bridges. Accident Analysis \& Prevention, 39, 2007, 969-973, http://dx.doi.org/10.1016/j.aap.2007.01.004

SISIOPIKU, V.P., AKIN, D. 2003. Pedestrian behaviors at and perceptions towards various pedestrian facilities; an examination based on observation and survey data. Transportation Research Part F, 6, 2003, 249-274, http://dx.doi.org/10.1016/j. trf.2003.06.001

SONI, N., SONI, N. 2016. Benefits of pedestrianization and warrants to pedestrianize an area. Land Use Policy, 57, 2016, 139-150. http://dx.doi.org/10.1016/j.landusepol.2016.005.009

ŠUCHA, M., DOSTÁL, D., RISSER, R. 2017. Pedestrian-driver communication and decision strategies at marked crossings. Accident Analysis and Prevention, 102, 2017, 41-50, http://dx.doi. org/10.1016/j.aap.2017.02.018

UTVM, 2017. The database GIS “Unified Transport Vector Map" online, [cited 2017-07-21]. Available at: http://www.jdvm.cz/

WICRAMSAHINGHE, V., DISSANAYAKE, S. 2017. Evaluation of pedestrians sidewalk behavior in developing countries. Transportation Research Procedia (World Conference on Transport Research Society), 25C, 2017, 4072-4082, http://dx.doi. org/10.1016/j.trpro.2017.05.327 